\title{
CEEC Accession Countries and the EMU - An Assessment of Relative and Readiness for Euro-Area Membership
}

\author{
Tomasz Kozluk \\ European University Institute
}

\begin{abstract}
Eastward enlargement of the Eurozone will result in transition economies sharing a currency with well-established market economies. We compare the suitability of the candidates relative to current members at a similar time before joining, as well as their readiness to comply with Maastricht criteria. Using fuzzy clustering and principal components, we assess patterns of convergence, possible inhomogeneities within the future Eurozone and create readiness and suitability indexes. We find the CEECs more suitable in terms of OCA criteria and more ready than some of the current members once were. Moreover, they are not found to follow distinct convergence paths.
\end{abstract}

- JEL Classifications: F33, F0, F15, C6

- Key words: EMU, Nominal convergence, Real convergence, OCA, Accession countries, CEECs

\section{Introduction}

On the 1st of May 2004 ten European countries joined the European Union. The enlargement agreement does not allow for any opt-out clause, as in the case of the U.K. and Denmark, thus these countries will be bound to eventually enter the European Monetary Union. Due to the entry requirements, this should not happen earlier than 2007. As the benefits of joining the common currency seem significant,

\footnotetext{
*Corresponding address: Tomasz Kozluk, Department of Economics, European University Institute, Villa San Paolo, Via della Piazzuola-43, 50133 Florence, Italy, Tel: +39-3495-4593-49, Fax: +39-055-4685902, E-mail: Tomasz.Kozluk@iue.it

(C2005-Center for International Economics, Sejong Institution, All Rights Reserved.
} 
it is often argued that it would be desirable for the candidate countries to adopt the euro unilaterally (see for example Nuti 2002, Coricelli 2002, Bratkowski and Rostowski 2002). This option, however, is strongly discouraged by the EU, and therefore does not seem plausible for the time being. This means, that the candidate countries will have to fulfill the entrance criteria posed by the Maastricht Treaty. But are they all ready to fulfill these requirements? Are they, in general, suitable for common currency area membership? Will this be done through steady convergence, or be a one-time effort and perhaps yield problems in complying with the Stability and Growth Pact or any arrangement that may replace it?

This paper aims to find whether and how the Central European accession countries tend to fit in the patterns distinguished among current members of the EMU. The exercise searches for similarities among the convergence towards common currency adoption of the current Eurozone states and that of candidate countries. In order to shed some light on the performance of the accession states, the analysis looks at how they fit in the core and north/south periphery partition found in previous work.

Below, the Maastricht Criteria are used to give an idea about readiness, and the effort it will take to fulfill the entry requirements, while the Optimum Currency Area characteristics serve to judge the suitability of the accession countries, relative to current members. Historically, the 8 Central-Eastern European enlargement states are former communist countries with centrally planned economies, 6 of them formed parts of other countries, and in fact of other currency unions, just slightly more then ten years ago. This suggests significant differences from the current members.

If the CEECs can be found to exhibit strong, persistent dissimilarities in comparison to EMU members, this may be an indication that they may be significantly less suitable for EMU, or add to the inhomogeneity of the Eurozone. In this case, entrance will have an impact on monetary policy and vice versa. While finding they converged in a similar way as current members did can help predict the impact of a common currency by looking at Eurozone states and their troubles in complying with the SGP, their potential gains and losses from joining the Euro. The idea of this simple experiment is to apply fuzzy clustering to look for partition among a set of current EMU members and accession states, as possible entrants to the euro area. The results are confronted with that of another multivariate analysis tool - principal components, which serves for the creation of 'readiness' and 'suitability' indexes for the candidate countries and relating them to 
current Eurozone states.

As both the Maastricht Criteria and Optimum Currency Area criteria are argued to be endogenous, comparing countries already in with candidates would be problematic and in effect, undesirable. Instead, this paper focuses on an 'out-oftime' analysis, that is, it looks at data at a certain period of time before accession, assuming the earliest possible entry date for the CEECs 2007, and compares candidate countries with members, within $n$ years before entry. That is, we perform comparative statics looking at the year 2007- $n$ for CEECs, 2001- $n$ for Greece and 1999- $n$ for the other Euro states. This 'out of time' analysis is certainly not flawless, but has the advantage of avoiding the ex ante vs. ex post problem. Among the drawbacks, the most serious is definitely the fact that changes of all the other characteristics -the so called 'state-of-the-world' are ignored. These include various aspects, somewhat external to our analysis, as the fact of EU membership, ERM participation and generally substantially different monetary regimes, levels of European integration, state of the world economy and integration and technology differences between 1980s and 1990s. Amid these reservations, the methodology pursued still seems to yield a reasonable trade-off, although conclusions must be drawn with reservation.

As a result of operationalizing OCA theory, we tend to find a concentric coreperiphery structure of the potential common currency area, with the CEECs, blending into this pattern. The transition countries converge well enough, that within 5 years of EMU membership, become classified as well distributed in the core- periphery pattern, where closeness to Germany seems to govern suitability. In terms of nominal convergence, some CEECs, namely the Baltic states and the Czech Republic exhibit higher readiness to fulfill the Maastricht criteria than most current members did within 5 years of entry. In fact, although often starting from a far away position, according to the methodology used, none of the transition countries are, within 5 years of potential Eurozone membership, less ready to qualify then the EMU outliers where at a similar point.

\section{The Optimum Currency Area}

The OCA theory was developed by Mundell (1961) and McKinnon (1963) and according to the primary view, an optimal currency area is a fairly homogenous region with synchronized business cycles and symmetric response, flexible prices and factor mobility. A more recent overview of the theory can be found in Tavlas 
(1993). The author mentions the following characteristics of optimal participants of a common currency zone:

- Synchronization of business cycles and supply/demand shocks - similar cycles, shocks and reactions reduce the necessity of separate monetary policy,

- Similarity of inflation rates - OCA theory attributes similar levels of inflation to similar preferences on inflation, thus a low cost of joining a common currency,

- Factor mobility - when high, is seen as a substitute for exchange rate movements in promoting external adjustment,

- Price and wage flexibility - Less rigidity among or between regions results in a less likely occurrence of the situation when one region is troubled by high unemployment and the other by high inflation because of the lack of scope for real exchange rate adjustment. Therefore, flexibility serves also as a shock absorbing mechanism,

- Goods market integration - countries with a similar production structure are less prone to asymmetric shocks, and thus face lower costs of fixing their currencies to each other, and pursuing a common monetary policy,

- Openness and economy size - open economies tend to prefer fixed exchange rates, as exchange rate movements have bigger disruptive effects than in relatively closed economies,

- Trade integration - joining a common currency disposes of the exchange rate risk associated with trading, thus is more favorable for countries which trade intensively with each other,

- Degree of commodity diversification - highly diversified economies are less vulnerable, when hit by sector-specific shocks,

- Small need for real exchange rate volatility - historically low exchange rate volatility suggests low cost of fixing the currencies,

- Fiscal integration - a high level of fiscal harmonization between countries, allows for inter-regional transfers that aim at smoothing out the effects of diverse shocks.

The theory of the Optimum Currency Area has been highly criticized as the sheer fact of joining a common currency area is associated with a major change in the economy of a country.

Frankel and Rose (1998) suggest that the major problem of evaluating whether countries should join a common currency is the fact that the above criteria are 
highly endogenous. Thus, by looking at ex-ante indicators, one cannot draw definite conclusions on the optimality of a currency union. A candidate seeming unfit for a monetary union when looking at historical OCA indicators may well turn out an optimal member once in. The sole fact of joining a common currency changes the nature of the OCA variables. In fact, a monetary union will most probably foster an increase in trade integration. Business cycle correlation can change as a consequence of this, though the theory is not consistent about in which direction. More integration, through Intra-Industry Trade may foster convergence and synchronization of the cycles, but on the other hand may lead to specialization (see for example Krugman and Venables 1993) and higher proneness to asymmetric shocks. Since the theoretical predictions are ambiguous, Frankel and Rose (1997) look at the data, and claim to find strong support for the first scenario.

As for the inflation rate similarity criteria, it is important to notice that OCA theory was mainly developed under the belief of the inflation-unemployment tradeoff (Philips curve). Taking the later recognized, vertical long-run Philips curve, suggests that the inflation in a country may not be actually the result of inflation preference, but perhaps of the credibility of the policy makers. Supposedly, entering a monetary union should improve credibility, thus make easier the maintenance of lower inflation.

Even labor mobility can be suspected of being endogenous. Bertola (1989) as cited in Tavlas (1993) proposes a model in which fixing the exchange rate reduces the income risk between the regions, and thus fosters more interregional mobility. Fiscal integration may in fact worsen the response to country specific shocks, as the local policies may perhaps, be finer tuned to deal with them.

Summarizing, the suspected endogeneity of the OCA criteria poses a threat to the credibility of ex-ante analysis, though in fact historical indicators are sometimes the only tools available. This is actually an argument in favor of using similarity and convergence to member countries, at the similar stage prior to entry, in order to shed some light on possible outcomes for the candidates.

\section{Accession Countries and the Eurozone}

After the accession to the EU, the Central European countries will be required to join the EMU 'as soon as they will be ready'. One of the most stressed advantages would be the credibility gain, since the full adoption of the euro, despite historical cases of currency unions' breakdowns, seems a very strong and trustworthy 
commitment. The loss of the exchange rate as an adjustment mechanism for absorbing asymmetric shocks does not seem a primary concern, as it is not certain whether it serves this purpose or contrarily is a source of disturbances itself. Therefore, it can be expected that CEECs will not only be obliged to, but also aim for entering the EMU as soon as possible (see for example Nuti 2002, Coricelli 2002, Bratkowski and Rostowski 2002 for an argument in favor of euroization). The entry conditions discussed below include EU membership and require a two year examination period. Thus, 2007 is probably the earliest plausible date for Eurozone accession, and will be the default date in the analysis conducted.

\section{A. The Maastricht Treaty Criteria}

The Maastricht Treaty of 1992, defined nominal prerequisites of the economy, necessary for EMU membership. Among the requirements to be fulfilled by candidates are:

- for two years prior to entry date:

$\circ$ the nominal exchange rate remaining within the \pm 15 per cent ERM II bounds,

- for one year prior to entry date:

$\circ$ the inflation rate no more than 1.5 per cent points above the average of the three EU members with lowest inflation,

- the interest rate on long-term government bonds no more than $2 \%$ points above the average of the three low-inflation countries,

- budget deficit not exceeding 3 per cent of GDP,

$\circ$ government debt not higher than 60 per cent of GDP,

At least two issues are worth noting: first of all, the last two of the so called 'Maastricht Criteria' have been applied somewhat less strictly to current EMU members, as they are accompanied by a clause which allows for higher values if converging or on an exceptional basis. Second, the inflation and interest rate criteria are assessed relative to EU, not EMU members, and thus may, in fact be judged relative to the applicants themselves.

The above criteria have been widely criticized (see for instance Buiter et al. 1992, Bratkowski and Rostowski 2002), mainly for the arbitrarity of the values and for accounting only for the nominal side of convergence and stability, while ignoring the real side. They do not account for any cyclical adjustments, do not distinguish between various types of public spending, are to a large degree 
endogenous and take into examination a very short period. The assessment of the appropriateness of the criteria is not the point of this paper, but as most probably forming the obligatory benchmark, they will be used below for the evaluation of the readiness of accession countries for Eurozone membership.

As mentioned, the accession countries upon joining the EU will be bound to enter the EMU, as no opt-out clause has been allowed. Hence, they will be obliged to fulfill the Maastricht criteria, as the Eurozone current members have. Below, we take a rough look at the performance of the eight CEE candidate countries, according to the Maastricht requirements, and compare their situation to the one of current EMU states within a similar amount of years before entering the common currency.

\section{The Data}

The EMU candidate CEECs have undergone transition from centrally planned towards market economies. This process is actually still continuing, but undoubtedly there has been a major structural break in the end of the 1980s and the beginning of the 1990s in the characteristics of these economies. Data produced by statistical offices of the centrally planned economies is not only itself unreliable, but additionally in the first years of transition after a landslide, the countries experienced a spectacular rebound. Therefore the figures, if at all available, can be expected to be imprecise. Thus, any data before, say, 1993 is practically useless, and data for the early years must be treated with extreme caution. This problem flaws the actual choice and construction of the variables for analysis, making them far from ideal.

As mentioned, the analysis takes a specific 'out of time' approach, that is comparing countries within a certain amount of years before joining the currency union. Hence for instance, assuming the CEECs aim for entering the Eurozone in 2007, the analysis conducted for 5 years prior to membership will compare 2002 data for the accession countries, 1996 data for Greece and 1994 data for the other EMU states.

There is no obvious way to discriminate against each other the criteria used in this analysis, thus all the variables have been standardized by subtracting the mean and dividing by the respective standard deviation.

\section{A. Real Convergence Variables}


As seen before, OCA literature suggests a number of criteria which make a country more likely to be suitable for common currency membership. The variables chosen for our analysis are: business cycle correlation, nominal exchange rate volatility, labor market flexibility, trade integration and inflation rate. The first two of the above are measured with respect to Germany, thus we are in a sense assessing the suitability of countries to adopt a common currency together with Germany. Therefore evidently, the reference core used later for the calculation of the OCA index will be Germany.

The business cycle variable is in fact more of a measure of correlation of industrial production fluctuations, due to the fact that, as explained above, shortness of the sample limits the estimation of business cycles for the CEECs. The reference is Germany, and the correlation is based on smoothed (HP-filter) monthly data in the period of 8 years, thus time invariant - a simplification necessary to avoid the disruptive influence of early 1990s data for the CEECs, and comparability with EMU-11. The real exchange rate volatility against Germany is captured monthly observations over 2 year moving windows.

Labor market flexibility in fact proxied by a measure of the easiness of new job creation - an aggregate index created upon variables such as the duration and complexity of new business registration procedures, as well as the cost of these procedures and minimum capital required relative to GNI. Another suggested proxy was employment protection legislation, which was not used due to the fact that it would be measuring some demand side flexibility - ambiguously related to the capability of the labor market to adjust to shocks. It seems indeed unclear whether more strict employment protection would lead to less severe effects of negative shocks on economy, or contrarily slow down the speed of adjustment and lead to more persistent shocks.

The degree of trade integration is measured as the share of trade done with the current EMU members. The accession countries, though not formally EU members exhibit relatively high integration with the Euro- 11 comparable with that of current members. More precise description of the data sources and variables creation can be found in the Appendix. Among the intentions of the real-side analysis is the Suitability Index - a one dimensional measure, capturing the relative suitability, according to OCA theory, for the Eurozone.

\section{B. Nominal Convergence Variables}

The choice of indicators in order to measure the readiness of countries in terms 
of Maastricht criteria is relatively straightforward. Data for inflation, monthly exchange rate against the ECU and Euro, budget deficit and public debt are generally available. The long term interest on government bonds poses a minor problem, especially in case of the candidate countries, thus has been proxied using the average market lending rate. In order to introduce reference points, two dummies have been added -Dummy(0) with all the variables set to zero and Dummy(MC) with all variables set to marginally fulfilling the MC. In fact, the set of countries does not provide a reference as in the case of real convergence criteria - Germany is not performing exceptionally in terms of nominal criteria fulfillment, thus the Dummy(0) serves for this purpose, while Dummy(MC) serves as a cut-off value. In other words, being classified far from Germany, in terms of the nominal variables, would not necessarily mean performing worse than Germany. In order to capture countries that score better on the Maastricht criteria than obliged, we adopted Dummy $(0)$ as the reference value, while Dummy(MC) is the furthest away in terms of all requirements, among the combinations still satisfying the treaty.

The details concerning creation of the variables are presented in the Appendix. One of the results of our nominal analysis is the Readiness Index - intended to be a one dimensional measure to score the readiness of countries to fulfill the Maastricht requirements.

\section{The Methodology}

For each of the sets of criteria, the analysis consists of two parts and the results are subsequently compared. In the first step, the fuzzy clustering algorithm is applied to search for a pattern in the data. Second, principal component analysis is used in an attempt to simplify the multivariate dataset with the intention of creating a relative one-dimensional measure.

\section{A. Fuzzy Clustering Algorithm}

The fuzzy clustering algorithm ${ }^{1}$, used to partition the data, can be seen in more detail in Kauffman and Rousseeuw(1990) or in Höppner et al.(1999). The exact method employed is the k-means method proposed by Dunn (1974) and Bezdek(1974). This follows the work of Artis and Zhang(1998b) and Boreiko (2003).

\footnotetext{
'The algorithm has been coded by the author in MatLab 6.5 and is available upon request.
} 
In our case, the dataset consists of $n$ countries, and $p$ variables. Each object $x_{i}$ is characterized by a vector of features $\left(x_{i}=\left\{x_{i 1}, . ., x_{i p}\right\}\right.$ for $\left.i=1 . . n\right)$, where each variable is standardized with mean zero and unit variance. The dissimilarity index $d(i, j)$ is the Euclidian distance between the two objects $x_{i}$ and $x_{j}$ in $p$-dimensional space:

$$
d(i, j)=\sqrt{\sum_{k=1}^{p}\left(x_{i k}-x_{j k}\right)^{2}}
$$

The objective of the algorithm is to minimize the following objective function $G$ :

$$
G=\sum_{k=1}^{m} \frac{\sum_{i=1}^{n} \sum_{j=1}^{n} u_{i k}^{2} u_{j k}^{2} d(i, j)}{2 \sum_{j=1}^{n} u_{j k}^{2}}
$$

Subject to the following constraints:

$$
u_{i j} \geq 0, \sum_{j} u_{i j}=1, \text { for } i=1 . . n, j=1 . . m
$$

The outcome of the algorithm is a matrix $U_{n x m}$, where element $u_{i j}$ is the membership coefficient, or the "degree of belongingness" of object $i$ to cluster $j$, while $m$ is the number of clusters. Elements in each of the $n$ rows sum up to 1 . For each object $i$, a relatively high value of one of the membership coefficients $u_{i j}$ allows for assigning $i$ to hard cluster $j$ with high certainty.

As for diagnostics, in order to assess how well partitioned the data are, the following Dunn normalized coefficient will be used:

$$
F_{m}=\frac{m \sum_{i=1}^{n} \sum_{j=1}^{m} \frac{u_{i j}^{2}}{n}-1}{m-1}
$$

The above takes values from 0 - complete fuzziness, when membership indices have the same value, to 1 - no fuzziness, when each object is assigned to a certain cluster with the membership coefficient of 1 . In the latter case we can speak of a 'clear' or 'hard' partition.

A measure of the quality of classification, the silhouette width of object $i$ is calculated as follows: 


$$
s(i)=\frac{b(i)-a(i)}{\max [a(i), b(i)]} \quad-1<s(i)<1
$$

where $a(i)$ is the average dissimilarity of $i$ from all objects in the same cluster and $b(i)$ the minimum (across all other clusters) of the average dissimilarity of $i$ from all the other objects in each single cluster. When $s(i)$ is close to one, this implies that $a(i)$ is small with respect to $b(i)$, that is, the object is well classified in the appropriate cluster. If $s(i)$ is close to zero, this implies that $a(i)$ and $b(i)$ are approximately equal, thus it is unclear which cluster should $i$ belong to. Negative $s(i)$ implies $i$ is assigned to the wrong cluster. Silhouette width values for clusters and the whole dataset indicate the quality of respectively cluster and total partition. In order to choose the optimal number of clusters $m$ average silhouette maximization has been applied.

\section{B. Principal Component Analysis}

Principal component analysis is a multivariate analysis tool, which aims reducing the number of variables in the data. In fact, in a multi-variable dataset, it is often the case that groups of variables move together. This may be a sign of the redundancy of information as variables may be driven by common underlying forces, thus being only a realization of the core structure of the dataset. Extracting the primary components allows for a simplification of the data by replacing the variance of a group of variables with a single new one. Each principal component is a linear combination of the original variables, that is the data matrix $X$ with $n$ observations and $p$ variables can be transformed into the $Z$ matrix, where:

$$
Z_{i}=\alpha_{i 1} x_{1}+\alpha_{i 2} x_{2}+\ldots++\alpha_{i p} x_{p} \quad \text { for } \quad i=1 \ldots p
$$

Principal components have two distinctive features:

- the $p$ components are orthogonal to each other, thus there is no redundancy of information,

- the first component explains the largest percentage of the variation in the original p-dimensional dataset (the second principal component explains the second largest percentage and so on). Although there is not necessarily a pure dimensional gain (there are $p$ principal components, from $p$ initial variables if not perfectly co-linear), often, the first few principal components account for most of the variation while the contribution of the rest is negligible.

The problem of extracting principal components is basically obtaining the 
eigenvectors and eigenvalues of the data correlation matrix, and arranging the eigenvalues in decreasing order. The highest eigenvalue will distinguish the first principal component and the corresponding eigenvector will contain the variable loadings - that is the $\alpha$ 's.

The application of principal component analysis in creating aggregate indexes for multi-variable analysis follows the work of Nicoletti et al. (1999) and is generally a method of classical multi- dimensional scaling. The reduced dimension framework allows for creating a more straightforward index of 'closeness', data patterns presentation, partition and interpretation. In the first step, Bartlett's $\chi^{2}$ test is used for finding the dimensionality of the dataset, which is then used as guidance for selecting the number of principal components used for creating the index. Second, the principal components themselves are extracted and the old dataset is transformed with respect to them. The following requirements are used to find the exact number of components preserved for further analysis:

- cumulatively, they explain at least 60 per cent of the sample variance,

- each of the components is associated with an eigenvalue greater than 1 ,

- individual contribution of each principal component in explaining overall variance is at least 15 per cent.

Next, upon the previously selected most significant components, the weighted Euclidian distance from the reference values is taken:

$$
I N D(i)=\sqrt{\frac{\sum_{j=1}^{m}\left(z_{i j}-z_{R j}\right)^{2} w_{j}}{\sum_{j=1}^{m} w_{j}}}
$$

where $m$ is the selected number of principal components, $w_{j}$ is the percent of variance explained by component $j, z_{i j}$ is the value of new variable $z_{j}$ for country $i$ (see equation 7). The reference values $R$ are: in the case of Real Convergence - Germany, and in the case of Nominal Convergence - Dummy(0). As the purpose of the component extraction is the formation of the indexes we will not be troubled by the interpretation of the components themselves, which often proves to be problematic.

The main weakness of the principal components approach is the sensitivity to basic data modifications. Revisions, updates or inclusions of other countries affect the variance of the dataset, and thus the principal components themselves. 


\section{Results and Discussion}

Clustering appears to be an interesting method of analyzing EMU convergence. Appropriately, allowing for a fuzzy partition permits us to make use of a much broader spectrum of information. The main advantage over hard clustering is that observations, in our case countries, are not strictly allocated to single clusters, but given a coefficient of belongingness to each cluster. This allows the determination, not only of similarities between countries inside the clusters, but also the of the inter-cluster country correspondence, as well as of similarities between clusters. The application of principal components introduces more rigor to the results and allows the formation of suitability and readiness indexes, which though rough, give a clearer idea on how candidates perform relative to each other in terms of optimum currency area membership and Maastricht criteria compliance.

\section{A. OCA Criteria}

The results of fuzzy cluster analysis applied to the OCA criteria are displayed in Table 1. Due to the fact that two out of five variables are time invariant proxies,

Table 1. Fuzzy clustering results - OCA

\begin{tabular}{|c|c|c|c|c|c|c|c|c|c|c|c|c|}
\hline \multicolumn{7}{|c|}{ OCA criteria - 11 years before EMU } & \multicolumn{6}{|c|}{ OCA criteria - 5 years before EMU } \\
\hline & \multicolumn{5}{|c|}{ Clusters } & Country & \multicolumn{5}{|c|}{ Clusters } & \multirow{2}{*}{$\begin{array}{l}\text { Country } \\
\text { Silhouette }\end{array}$} \\
\hline & I & II & III & IV & $\mathrm{V}$ & Silhouette & I & II & III & IV & V & \\
\hline Austria & 0.77 & 0.07 & 0.08 & 0.06 & 0.02 & 0.84 & 0.42 & 0.25 & 0.25 & 0.05 & 0.03 & 0.50 \\
\hline Belgium & 0.76 & 0.07 & 0.09 & 0.05 & 0.02 & 0.81 & 0.44 & 0.26 & 0.23 & 0.05 & 0.03 & 0.46 \\
\hline Finland & 0.11 & 0.43 & 0.11 & 0.27 & 0.07 & 0.89 & 0.11 & 0.13 & 0.08 & 0.60 & 0.07 & 0.82 \\
\hline France & 0.66 & 0.16 & 0.09 & 0.07 & 0.02 & 0.76 & 0.70 & 0.19 & 0.06 & 0.04 & 0.01 & 0.73 \\
\hline Germany & 0.49 & 0.20 & 0.14 & 0.11 & 0.06 & 0.72 & 0.47 & 0.27 & 0.15 & 0.07 & 0.04 & 0.67 \\
\hline Greece & 0.00 & 0.00 & 0.00 & 0.00 & 1.00 & 1.00 & 0.00 & 0.00 & 0.00 & 0.00 & 1.00 & 1.00 \\
\hline Ireland & 0.12 & 0.52 & 0.11 & 0.21 & 0.04 & 0.89 & 0.16 & 0.17 & 0.09 & 0.53 & 0.04 & 0.70 \\
\hline Italy & 0.86 & 0.05 & 0.05 & 0.02 & 0.01 & 0.83 & 0.16 & 0.41 & 0.29 & 0.11 & 0.03 & 0.58 \\
\hline Netherlands & 0.49 & 0.23 & 0.12 & 0.10 & 0.06 & 0.52 & 0.57 & 0.21 & 0.11 & 0.08 & 0.03 & 0.74 \\
\hline Portugal & 0.43 & 0.12 & 0.28 & 0.08 & 0.08 & 0.54 & 0.12 & 0.22 & 0.58 & 0.04 & 0.05 & 0.73 \\
\hline Spain & 0.66 & 0.09 & 0.17 & 0.05 & 0.03 & 0.73 & 0.07 & 0.19 & 0.70 & 0.02 & 0.02 & 0.43 \\
\hline Czech R. & 0.63 & 0.08 & 0.21 & 0.05 & 0.03 & 0.63 & 0.26 & 0.42 & 0.24 & 0.05 & 0.02 & 0.48 \\
\hline Estonia & 0.10 & 0.24 & 0.20 & 0.42 & 0.04 & 0.52 & 0.47 & 0.25 & 0.12 & 0.13 & 0.04 & 0.61 \\
\hline Hungary & 0.12 & 0.10 & 0.55 & 0.17 & 0.06 & 0.67 & 0.03 & 0.06 & 0.89 & 0.01 & 0.01 & 0.72 \\
\hline Latvia & 0.05 & 0.25 & 0.12 & 0.56 & 0.03 & 0.57 & 0.09 & 0.11 & 0.05 & 0.72 & 0.02 & 0.55 \\
\hline Lithuania & 0.07 & 0.15 & 0.15 & 0.57 & 0.07 & 0.68 & 0.05 & 0.05 & 0.03 & 0.84 & 0.02 & 0.82 \\
\hline Poland & 0.10 & 0.07 & 0.68 & 0.12 & 0.03 & 0.61 & 0.19 & 0.40 & 0.22 & 0.15 & 0.04 & 0.72 \\
\hline Slovakia & 0.17 & 0.17 & 0.42 & 0.19 & 0.05 & 0.46 & 0.15 & 0.55 & 0.24 & 0.04 & 0.02 & 0.48 \\
\hline Slovenia & 0.65 & 0.07 & 0.20 & 0.05 & 0.04 & 0.65 & 0.13 & 0.17 & 0.59 & 0.04 & 0.06 & 0.76 \\
\hline Cl. Silhouette & 0.70 & 0.89 & 0.58 & 0.59 & 1.00 & 0.7012 & 0.62 & 0.56 & 0.66 & 0.72 & 1.00 & 0.6578 \\
\hline Dunn Coeff. & & & & .3124 & & & & & & 3138 & & \\
\hline
\end{tabular}


only two periods of examination have been taken: 11 and 5 years before potential accession. In both the optimal number of clusters is 5 , and the data exhibits quite a high degree of fuzziness - the Dunn's normalized coefficient is in equal to 0.31 .

This strengthens the argument for using the fuzzy version of the clustering algorithm. Moreover, in both cases the partition appears quite sound - none of the countries are misclassified, and the lowest object silhouette is 0.46 .

We consider Germany as the default common currency member in the whole of Real Convergence analysis. Thus, within 11 years before potential adoption of the Euro, 'the core', that is the countries most suitable to join, lies between cluster I and II. Germanys', and hence 'the cores' coefficients are 49 per cent and 20 per cent respectively. The country with almost identical distribution among clusters is the Netherlands, and thus is the primary candidate for joining Germany in a common currency, exhibiting low inflation and real exchange rate volatility, high trade integration and labor market flexibility, together with an average business cycle correlation. Next is France, with a high business cycle correlation and less flexible labor market. Austria and Belgium are found very similar to each other, and moreover very close to the core. Italy is also close to the two, except for a higher inflation level. Further away, though still in cluster I there are: Portugal and Spain joined by the Czech Republic and Slovenia. Eleven years before accession these exhibit a large degree of similarity. Cluster II with Finland and Ireland, though with coefficients of 43 per cent and 52 per cent, is characterized by low trade integration and business cycle correlation, high labor market flexibility and medium real exchange rate volatility. Both, but especially Finland, show high resemblance with the three Baltic States, classified in a separate cluster (IV) mainly due to higher inflation and exchange rate volatility. Greece remains in a separate cluster, which suggests that according to OCA criteria, in 1990, 11 years before acceding to the EMU, Greece was not part of the German based optimal currency area. Cluster III, composed of Hungary, Poland and Slovakia - characterized by high business cycle correlation, exchange rate volatility and inflation, and low labor market flexibility. If we consider the fact that all CEECs excluding Lithuania (15 per cent) and Latvia (12 per cent) have coefficients of belongingness to this cluster higher than 20 per cent, we can interpret this as the Central European periphery. It is worth noting that this cluster exhibits high similarity to Portugal (28 per cent) and noticeable to Spain (17 per cent).

Table 2 shows the cluster characteristics, which together with the results in Table 1 allow us to roughly sketch a primary view of the pattern: 
Table 2. OCA 11 years before EMU - cluster characteristics.

\begin{tabular}{lccccc}
\hline \multicolumn{1}{c}{ Hard Clusters } & $\begin{array}{c}\text { Business } \\
\text { Cycle }\end{array}$ & $\begin{array}{c}\text { Real Ex. } \\
\text { Vol. }\end{array}$ & $\begin{array}{c}\text { Labor } \\
\text { Mkt. }\end{array}$ & $\begin{array}{c}\text { Trade } \\
\text { Int. }\end{array}$ & Inflation \\
\hline IT, AUS, BEL, FR, SP, SLN, CZ, & Med-Hi & Low-Med Med-Low & Med-Hi & Low-Med \\
GER, NL,PT & Low & Med & Hi & Low & Low-Med \\
FIN, IRL & Hi & Hi & Low & Med-Low & Hi \\
PL, HU, SLK & Low-Hi & Hi & Hi & Low & Hi \\
LIT, LAT, EST & Low & Low & Low & Hi & Hi \\
GR & & & & & \\
\hline
\end{tabular}

Table 3. OCA 5 years before EMU - cluster characteristics

\begin{tabular}{lccccc}
\hline \multicolumn{1}{c}{ Hard Clusters } & \multicolumn{1}{c}{ Business Cycle } & Real Ex. Vol. Labor Mkt. & Trade Int. & Inflation \\
\hline FR, NL, EST, GER, AUS & Hi-Med & Low & Med-Hi & All & Low-Med \\
SLK, CZK, IT, PL & Hi-Med & Hi-Med & Low-Med & Med & Low-Med \\
HU, SP, PT, SLN & Med-Hi & Med & Low & Hi & Hi \\
LIT, LAT, FIN, IRL & Low & Hi & Hi-Med & Low & Low-Med \\
GR & Low & Med & Low & Med & Hi \\
\hline
\end{tabular}

- The core- Germany, Netherlands, France, Austria and Belgium, followed by Italy and further by Spain, Slovenia, Czech Republic and Portugal.

- The northern periphery- Finland and Ireland, with some similarity to the Baltic States.

- The 'transition periphery'- mainly Poland, Hungary and Slovakia, but close to all other CEECs.

The picture changes significantly when we move 6 years forward. The transition countries, further away from the early 1990s' chaotic period, tend to stabilize the economies, successfully decrease inflation and increase the trade integration with current EMU members. Hence, the notion of the transition countries and current Euro states forming diverse clusters, fades away. The level of inhomogeneity is not as intense, and patterns composed of both CEECs and EU countries emerge. The core again lies between clusters I (Germany's coefficient 47 per cent) and II (Germany 27 per cent). Germany, France, Netherlands, Austria and Belgium show persisting strong resemblance. They are joined in cluster I by Estonia, which lowered its inflation substantially over this time, while accompanied by a strong decrease in real exchange rate volatility - thus became the primary CEEC candidate for the Euro in terms of OCA criteria. Though in a separate cluster (II) the Czech Republic and to a slightly lesser extent Poland and Slovakia, are also very close to the core - their fuzzy coefficients exhibit a strong similarity to Germany. Cluster III can be interpreted as a signal of existence of the southern periphery - relatively 
strong belongingness of Spain, Portugal, Hungary and Slovenia also joined by fairly similar Italy ( 29 per cent compared to 41 per cent in cluster II) -all with average real exchange volatility, high trade integration and inflation, and low labor market flexibility. Cluster IV indicates the strengthening of the ties between the Baltic States and the northern periphery, with the exception of Estonia which as indicated moved closer to Germany, due to persistently higher inflation and business cycle correlation, but still exhibits a coefficient of 13 per cent in the northern periphery due to low trade integration and a relatively flexible labor market. Greece tends to form a separate cluster, mainly due to negative business cycle correlation, low labor market flexibility, and very high inflation. Thus the pattern of inhomogeneities changed over the 6 year period, and can be summarized as follows:

- the core: Germany, Austria, Belgium, France and the Netherlands joined by Estonia;

- the southern periphery: Hungary, Spain, Slovenia and Portugal with significant closeness of Italy;

- the eastern periphery: Slovakia, Czech Republic and Poland, surprisingly close to the core and showing similarity with Italy but also Estonia and Slovenia;

- the northern periphery: Lithuania, Latvia, Finland and Ireland, with some persisting resemblance to Estonia;

- the persistent outlier: Greece, showing some weak similarities with the southern periphery;

Cluster analysis though yielding the emerging concentric core periphery pattern for real convergence, and the diffusion of the CEECs between the intra-EU peripheries, yet these results lack some rigor. They constitute a starting point and principal components are used to seek confirmation of relative convergence and performance according to the OCA criteria.

Table 4. OCA Analysis - two first PCs.

\begin{tabular}{ccc}
\hline OCA & \multicolumn{2}{c}{2 first components } \\
\hline & 11 years & 5 years \\
$1^{\text {st }}$ var. explained & 43.46 & 49.72 \\
$2^{\text {nd }}$ var. explained & 27.55 & 24.84 \\
\hline & Bartlett's test p-value \\
\hline $\mathrm{n}=2$ & 0.01 & 0.02 \\
$\mathrm{n}=3$ & 0.02 & 0.07 \\
\hline
\end{tabular}


Table 5. Suitability Indexes - authors own calculations.

\begin{tabular}{cccccc}
\hline & OCA 11 & OCA 5 & & OCA 11 & OCA 5 \\
\hline Austria & 0.62 & 0.57 & Spain & 1.01 & 1.07 \\
Belgium & 0.65 & 0.44 & Czech Rep. & 1.25 & 0.43 \\
Finland & 2.62 & 3.26 & Estonia & 2.66 & 0.85 \\
France & 0.64 & 0.36 & Hungary & 2.93 & 1.09 \\
Germany & 0.00 & 0.00 & Latvia & 2.78 & 1.95 \\
& & & & & \\
Greece & 2.51 & 2.96 & Lithuania & 4.26 & 2.98 \\
Ireland & 2.26 & 2.29 & Poland & 2.23 & 0.94 \\
Italy & 0.78 & 0.95 & Slovakia & 1.98 & 0.58 \\
Netherlands & 0.48 & 0.49 & Slovenia & 1.27 & 1.68 \\
Portugal & 1.49 & 1.50 & & & \\
\hline
\end{tabular}

The PCs analysis results displayed in Table 4(more details in the Appendix), are sufficient to allow focusing on the first two components, as in both cases they explained over 70 per cent of the variance and meeting other previously stated requirements. Bartlett's test yields the non-rejection of the dimension of the dataset equal 2 at 99 per cent confidence level in the case of 11 years prior entry and at 95 per cent level at 5 years prior to entry, thus together with the above information, allows the preservation solely the first two components for further analysis, without an important loss of information.

The OCA Suitability Index is used to judge relative convergence. It is a transformation into one dimension, hence results with the loss of some information compared to the PC graphs (Figure 2 and 4), and obviously compared to cluster analysis, but facilitates interpretation.

The country performance has been presented in Figure 1 (11 years) and Figure 3 (5 years). The first apparent observation is that OCA criteria discrimination is certainly negatively correlated with geographical distance from the core of the common currency (Germany). Eleven years before entry, the CEECs still constitute somewhat of a separate entity - there suitability is certainly lower than of most EU members, though still some sort of 'gravity' forces are visible. Five years before membership, the diversity of the former east-block plays a much smaller role, and the suggested 'gravity' pattern strengthens. The striking result is the apparent rings formed by Euro candidates - Germany's neighbors, excluding Poland seem most appropriate with OCA index values below 0.6 , then followed by the second group Italy, Poland, Spain, Hungary, and the furthest away geographically - Estonia, all below 1.2. The third group, constitutes the somewhat more peripheral Portugal and 
Slovenia - below 1.8. Finally, the two last groups from the ring of least suitable according to the OCA criteria - Latvia, Ireland, Lithuania and Finland from the north together with Greece from the south. This, somewhat gravitational pattern suggests that close trade and economical ties govern our criteria. In fact, the amount of trade done especially with Germany, combined with high business cycle correlation and low real exchange volatility exhibited by the countries with closest to Germany, overwhelm any fading influences of the transition for the CEECs. Further away geographically, these seem to matter less and thus the countries within larger distance form the peripheries.

The comparative statics approach yields:

- a group of stable optimum currency area members, consisting of Germany, France, Belgium, the Netherlands, and Austria;

- a group of converging states, changing fairly rapidly: Czech Republic, Slovakia, Estonia, Poland, Hungary, Latvia and somewhat further Lithuania; - a group of relatively close but stable countries: the southern periphery - Italy, Spain, Portugal joined by slightly diverging Slovenia;

- a group of outliers, which are, according to the criteria used, least optimal for the Euro: Ireland, and diverging Greece and Finland.

Figure 1. Mapping of OCA index for CEEC accession countries and EMU members 11 years before membership. Lower number (lighter color) indicates 'closer' to Germany in terms of OCA Criteria. Black - not classified. \{Own calculations\}

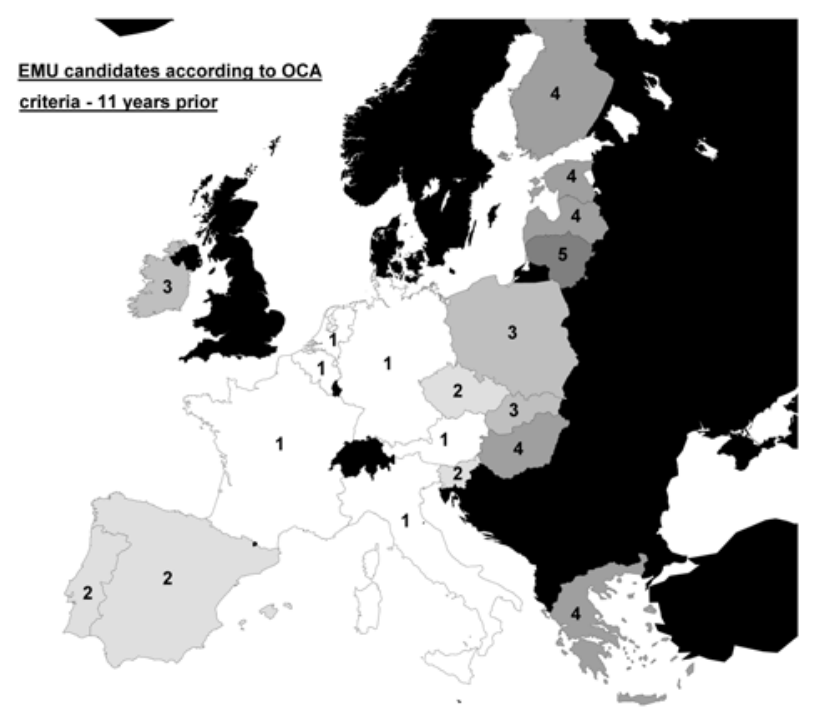


Figure 2. Comparison of clustering and principal components results. OCA criteria, CEEC accession countries and EMU members, 11 years before membership. First two components explain 71 per cent of variance. Different symbols indicate separate hard clusters. \{Own calculations\}

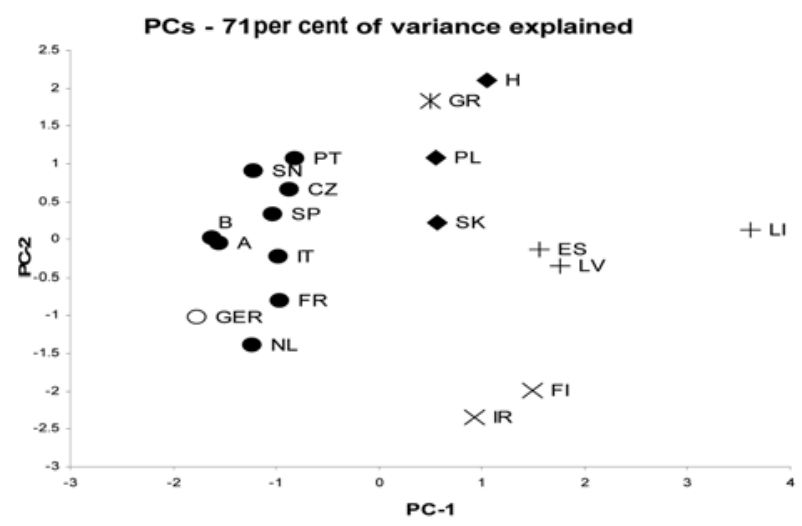

The fact that principal component analysis allows us the reduction of the dataset to two dimensions, preserving over 70 per cent of the variance, allows for a more informative illustration of OCA criteria performance.

Though perhaps a bit rough, the graphs of the first two of new variables obtained through PCs, allow for a comparison of our index creation methodology and cluster analysis. In Figure 2 (11 years) and Figure 4 ( 5 years) the different hard clusters are distinguished by different labels. In Figure 2 a clear distinction between the 'core' made up mostly of current EMU members excluding Greece and the far north - Finland and Ireland. The last two are distinguishably far from other clusters, but closest to the Baltic States. The eastern block countries tend to fit in the medium values of the first component and generally the cluster findings are well confirmed.

The two dimensional plot of the principal components analysis result 5 years prior to EMU membership, is visible in Figure 4. The northern periphery is apparent, similarly the southern - Portugal, Spain, Slovenia and Hungary are plotted fairly close to Italy, and less to the outlying Greece. Hard clusters I and II form the respectively the strict and wider core of the EMU. This somewhat confirms the notion that best fit for foregoing own currency are, according to OCA theory, small, open economies. The CEEC economies are relatively small compared to EU members and the level of openness is on average similar. Additionally, the apparent concentric core periphery pattern, suggests some sort of a gravity model seems to be a next step extension to capture appropriateness for the OCA. 
Figure 3. Mapping of OCA index for CEEC accession countries and EMU members 5 years before membership. Lower number (lighter color) indicates 'closer' to Germany in terms of OCA Criteria. Black - not classified. \{Own calculations

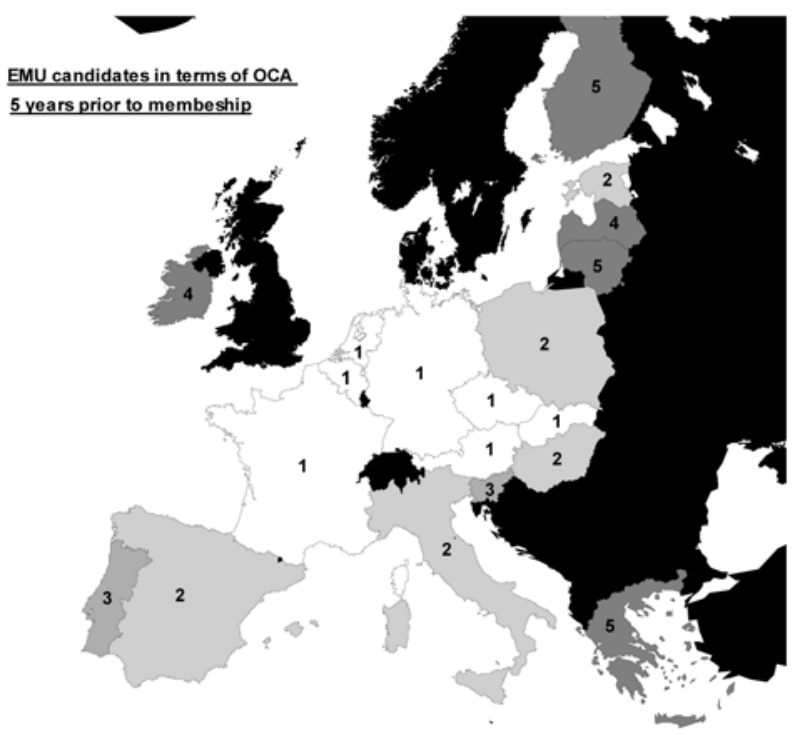

Figure 4. Comparison of clustering and principal components results. OCA criteria, CEEC accession countries and EMU members, 5 years before membership. First two components explain 75 per cent of variance. Different symbols indicate separate hard clusters. \{Own calculations\}

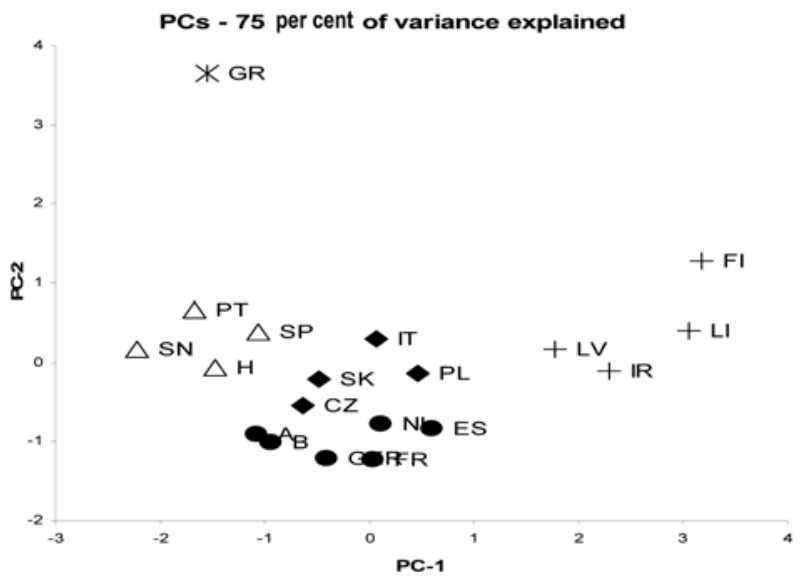

\section{B. Maastricht Criteria}

After constructing the OCA suitability indexes, we turn to assessing nominal convergence. The sheer fact that countries are found suitable to join the Eurozone according to the selected 'real' Optimum Currency Area variables, does not 
Table 6. Nominal Convergence - fuzzy clustering results.

\begin{tabular}{|c|c|c|c|c|c|c|c|c|c|c|c|c|c|c|c|c|c|c|c|c|c|c|c|c|c|}
\hline \multicolumn{9}{|c|}{ Maastricht Criteria 11 years before membership } & \multicolumn{8}{|c|}{ Maastricht Criteria 8 years before membership } & \multicolumn{9}{|c|}{ Maastricht Criteria 5 years before membership } \\
\hline \multicolumn{8}{|c|}{ Clusters } & \multirow{2}{*}{$\begin{array}{l}\text { Country } \\
\text { Silh. }\end{array}$} & \multicolumn{7}{|c|}{\begin{tabular}{|c|} 
Clusters \\
\end{tabular}} & \multirow{2}{*}{$\begin{array}{l}\text { Country } \\
\text { Silh. }\end{array}$} & \multicolumn{8}{|c|}{ Clusters } & \multirow{2}{*}{$\begin{array}{l}\text { Country } \\
\text { Silh. }\end{array}$} \\
\hline Country & 1 & $\|$ & III & IV & $\mathrm{v}$ & $\mathrm{VI}$ & VII & & 1 & $\|$ & III & IV & $\mathrm{v}$ & $\mathrm{VI}$ & VII & & 1 & ॥ & III & IV & $\mathrm{v}$ & $\mathrm{VI}$ & VII & VIII & \\
\hline Austria & 0.60 & 0.19 & 0.06 & 0.06 & 0.040 & $0.02: 0$ & 0.02 & 0.67 & 0.87 & 0.04 & 0.02 & 0.02 & 0.01 & 0.02 & 0.02 & 0.67 & 0.77 & 0.04 & 0.06 & 0.02 & 0.05 & 0.03 & $0.02: 0$ & 0.01 & 0.73 \\
\hline Belgium & 0.10 & 0.68 & 0.05 & 0.04 & 0.050 & $0.03: 0$ & 0.05 & 0.76 & 0.11 & 0.06 & 0.66 & 0.05 & 0.03 & 0.06 & 0.05 & 0.76 & 0.30 & $0.09 \mathrm{c}$ & 0.13 & 0.07 & 0.17 & $0.11: 0$ & 0.05 & 0.07 & 0.58 \\
\hline Finland & 0.20 & 0.09 & 0.27 & 0.22 & 0.110 & $0.07: 0$ & 0.04 & 0.54 & $0.12: 0$ & 0.25 & 0.03 & 0.44 & 0.05 & 0.090 & 0.04 & 0.54 & 0.08 & 0.05 & 0.58 & 0.02 & 0.09 & $0.15: 0$ & $0.02: 0$ & 0.01 & 0.25 \\
\hline France & 0.58 & 0.10 & 0.16 & 0.07 & 0.040 & $0.02: 0$ & 0.02 & 0.67 & 0.65 & 0.12 & 0.04 & 0.05 & 0.08 & 0.050 & 0.02 & 0.67 & 0.53 & 0.08 & 0.14 & 0.04 & $0.08: 0$ & $0.06: 0$ & $0.05: 0$ & 0.02 & 0.45 \\
\hline Germany & 0.55 & 0.15 & 0.15 & 0.06 & 0.050 & 0.020 & 0.02 & 0.67 & $0.76 \mathrm{c}$ & 0.10 & 0.03 & 0.03 & 0.03 & 0.030 & 0.02 & 0.67 & 0.47 & 0.16 & 0.09 & 0.08 & 0.07 & $0.06: 0$ & $0.04: 0$ & 0.03 & 0.38 \\
\hline Greece & 0.00 & 0.00 & 0.00 & 0.00 & 0.000 & 0.000 & 0.99 & 1.00 & 0.00 & 0.00 & 0.00 & 0.00 & 0.00 & 0.000 & 0.99 & 1.00 & 0.00 & $0.00 \mathrm{C}$ & 0.00 & 0.00 & 0.00 & $0.00: 0$ & 0.00 & 1.00 & 1.00 \\
\hline Ireland & 0.08 & 0.81 & 0.03 & 0.02 & 0.030 & $\begin{array}{l:ll}0.01 & 0\end{array}$ & 0.01 & 0.40 & 0.47 & 0.11 & 0.16 & 0.08 & 0.07 & 0.090 & 0.01 & 0.40 & 0.30 & $0.17 \mathrm{c}$ & 0.17 & 0.05 & 0.09 & $0.13: 0$ & 0.05 & 0.03 & 0.48 \\
\hline Italy & 0.16 & 0.30 & 0.06 & 0.08 & 0.110 & $0.08: 0$ & 0.21 & 0.45 & 0.06 & 0.05 & 0.75 & 0.03 & 0.02 & $0.05: 0$ & 0.21 & 0.45 & 0.11 & 0.06 & 0.14 & 0.06 & 0.36 & $\begin{array}{c:c}0.16 & 0\end{array}$ & 0.030 & 0.09 & 0.44 \\
\hline Netherland & 0.14 & 0.71 & 0.04 & 0.03 & $0.04: 0$ & $0.02: 0$ & 0.02 & 0.41 & 0.67 & 0.09 & 0.08 & 0.06 & 0.03 & 0.060 & 0.02 & 0.41 & 0.80 & 0.04 & 0.05 & 0.02 & 0.040 & 0.03 & $0.01: 0$ & 0.01 & 0.74 \\
\hline Portugal & 0.32 & 0.19 & 0.05 & 0.16 & 0.10 & 0.090 & 0.10 & 0.42 & 0.12 & 0.10 & 0.14 & 0.08 & 0.04 & 0.340 & 0.10 & 0.42 & 0.09 & 0.06 & 0.09 & 0.10 & 0.49 & $0.09: 0$ & $0.02: 0$ & 0.07 & 0.44 \\
\hline Spain & 0.57 & 0.10 & 0.05 & 0.10 & 0.110 & $\begin{array}{l:ll}0.04 & 0\end{array}$ & 0.03 & 0.64 & 0.31 & 0.25 & 0.08 & 0.11 & 0.03 & 0.200 & 0.03 & 0.64 & 0.08 & 0.05 & 0.14 & 0.04 & 0.470 & $0.18: 0$ & 0.020 & 0.02 & 0.33 \\
\hline Czech R. & 0.37 & 0.06 & 0.09 & 0.31 & 0.090 & $0.07: 0$ & 0.03 & 0.42 & 0.10 & 0.24 & 0.05 & 0.45 & 0.06 & 0.08 & 0.03 & 0.42 & 0.15 & 0.13 & 0.40 & 0.04 & 0.08 & 0.13 & 0.05 & 0.02 & 0.69 \\
\hline Estonia & 0.15 & 0.06 & 0.08 & 0.36 & 0.080 & $0.22: 0$ & 0.06 & 0.64 & $0.25:$ & 0.44 & 0.05 & 0.08 & 0.08 & 0.08 & 0.06 & 0.64 & 0.12 & 0.40 & 0.09 & 0.10 & 0.06 & $0.07: 0$ & $0.15: 0$ & 0.02 & 0.79 \\
\hline Hungary & 0.06 & 0.05 & 0.03 & 0.12 & 0.090 & $0.57: 0$ & 0.07 & 0.77 & 0.05 & 0.04 & 0.03 & 0.05 & 0.01 & 0.790 & 0.07 & 0.77 & 0.12 & 0.05 & 0.12 & 0.07 & 0.46 & $0.09: 0$ & $0.03: 0$ & 0.05 & 0.61 \\
\hline Latvia & 0.07 & 0.03 & 0.03 & 0.44 & $0.06: 0$ & $0.32: 0$ & 0.04 & 0.58 & 0.07 & 0.80 & 0.02 & 0.05 & 0.02 & $0.03: 0$ & 0.04 & 0.58 & 0.11 & 0.26 & 0.30 & 0.05 & 0.070 & $0.15: 0$ & $0.04: 0$ & 0.02 & 0.55 \\
\hline Lithuania & 0.04 & 0.03 & 0.02 & 0.11 & 0.06 & 0.710 & 0.04 & 0.56 & $0.14: \mathrm{c}$ & 0.38 & 0.11 & 0.19 & 0.06 & 0.10 & 0.04 & 0.56 & 0.13 & 0.22 & 0.25 & 0.05 & 0.07 & $0.14: 0$ & 0.12 & 0.02 & 0.60 \\
\hline Poland & 0.04 & 0.02 & 0.02 & 0.12 & 0.04 & 0.710 & 0.04 & 0.52 & 0.07 & 0.11 & 0.04 & 0.51 & 0.02 & $\begin{array}{l:l}0.23 & 0 \\
0 & \end{array}$ & 0.04 & 0.52 & 0.07 & 0.07 & 0.21 & \begin{tabular}{lll}
0.04 \\
\hdashline
\end{tabular} & 0.14 & 0.410 & $0.02: 0$ & 0.03 & 0.82 \\
\hline Slovakia & 0.66 & 0.05 & 0.06 & 0.14 & 0.050 & 0.030 & 0.02 & 0.72 & 0.05 & 0.06 & 0.03 & 0.07 & 0.02 & $0.75: 0$ & 0.02 & 0.72 & 0.03 & $0.83 \mathrm{i}$ & 0.03 & 0.030 & 0.02 & 0.030 & 0.020 & 0.01 & 0.77 \\
\hline Slovenia & 0.04 & 0.02 & 0.01 & 0.85 & 0.030 & $\begin{array}{ll:l}0.04 & 0\end{array}$ & 0.01 & 0.58 & 0.32 & 0.24 & 0.05 & 0.13 & 0.08 & $\begin{array}{l:l}0.17 & 0\end{array}$ & 0.01 & 0.58 & 0.00 & 0.00 & 0.00 & 0.99 & 0.00 & 0.00 & 0.00 & 0.00 & 1.00 \\
\hline Dum(0) & 0.02 & 0.01 & 0.95 & 0.01 & 0.010 & 0.00 & 0.00 & 0.56 & 0.00 & 0.00 & 0.00 & 0.00 & 0.99 & 0.00 & 0.00 & 0.56 & 0.00 & 0.00 & 0.00 & 0.00 & 0.00 & $0.00: 0$ & $0.99: 0$ & 0.00 & 1.00 \\
\hline $\operatorname{Dum}(\mathrm{MC})$ & 0.01 & 0.00 & 0.00 & 0.00 & 0.980 & 0.000 & 0.00 & 1.00 & 0.04 & 0.06 & 0.02 & 0.82 & 0.01 & 0.050 & 0.00 & 1.00 & 0.02 & 0.03 & 0.06 & 0.01 & 0.040 & $0.82: 0$ & $0.01: 0$ & 0.01 & 0.80 \\
\hline Cl. Silh. & 0.60 & 51 & 0.55 & 0.60 & $1.00 \mathrm{C}$ & 0.621 & 1.00 & $\mid 0.6186$ & 0.61 & 0.48 & 0.81 & 0.62 & 1 & 0.65 & 1 & 0.6186 & 0.56 & $0.78 \mathrm{C}$ & 0.52 & $1.00 \mathrm{C}$ & 0.460 & 0.811 & 1.001 & 1.00 & 0.6398 \\
\hline Dunn & & & & & 3873 & & & & & & & & .3965 & & & & & & & & 0.348 & & & & \\
\hline
\end{tabular}


necessarily mean that they will not have trouble in complying with the Maastricht 'nominal' requirements, thus does not imply actual EMU readiness. In this part we perform a similar analysis as above, but with respect to the Maastricht criteria.

Table 6 displays the cluster analysis results, for 11, 8 and 5 years before potential EMU accession. As contrary to the OCA exercise, all five of the variables used can be measured yearly, three periods are reported - this contributes to the analysis of the convergence patterns. In the three periods examined the degree of fuzziness if fairly high - between 0.34 and 0.40 . The optimal number of clusters is fairly high 7 and 8, but this may be in part attributed to the fact of inclusion of the two 'artificial' dummies that tend to cluster away from other objects. However generally, the average silhouettes are above 0.60 and none of the objects is misclassified - though in a three cases the object silhouettes are below 0.40 .

In the period of 11 years before EMU membership, we find Germany, France, Austria together with Spain and Portugal, the Czech Republic and Slovakia join this cluster, mainly because of fairly similar inflation, nominal exchange rate volatility and interest rates. This association is weakened by lower debt levels of the two transition economies. Cluster II contains countries with high budget deficit and public debt and relatively low inflation - Ireland, Netherlands, Belgium and to a lesser extent - coefficient of 30 per cent - Italy (mainly due to higher inflation). In fact Italy is also partitioned close to Greece (Italy's coefficient of 21 per cent in cluster VII), which though in a separate cluster, has similarly a very high deficit and high public debt, fairly low exchange rate volatility but much higher inflation and interest rate. Finland clusters somewhat between the core cluster I (20 per cent), cluster IV with Estonia, Latvia and Slovenia (22 per cent) and cluster III with the Dummy(0) (27 per cent) indicating in fact that it is closest to the zero values and, at least at this point, should have no problem complying with the Maastricht requirements. As emphasized before, the analysis of 11 years before Eurozone entry, is troubled by the somewhat chaotic period of rapid transition for the CEECs. Therefore, it is not surprising that the CEECs exhibit quite a high degree of correspondence, distinguishable from the EU members. Hence, clusters IV and VI are not only fairly similar to each other, but contain basically all CEECs excluding Slovakia. The latter shows some similarity with cluster IV(14 per cent), similarly to the Czech Republic (31 per cent) - due to similar performance: low deficit and debt together with high exchange volatility, interest and inflation. Cluster VI consists of Poland, Lithuania (both 71 per cent) and Hungary(57 per cent) - and is distinguishable from IV because of much higher deficit and debt. The 
Table 7. MC 11 years before EMU - cluster characteristics.

\begin{tabular}{lccccc}
\hline \multicolumn{1}{c}{ Hard Clusters } & $\begin{array}{c}\text { Budget } \\
\text { Deficit }\end{array}$ & $\begin{array}{c}\text { Public } \\
\text { Debt }\end{array}$ & $\begin{array}{c}\text { Nominal } \\
\text { Ex. Vol. }\end{array}$ & $\begin{array}{c}\text { Interest } \\
\text { Rate }\end{array}$ & Inflation \\
\hline SLK, AUS, FR, SP, GER, CZ, PT & All & Med-Low & Med-Low & Med-Low & Med-Low \\
IRL, NL, BEL, IT & Hi & Hi & Low-Med & Low-Med & Low \\
D(0), FIN & Low & Low & Low-Med & Low & Low-Med \\
SLN, LAT, EST & Low & Low & Hi & Hi & Hi \\
GR & Hi & Hi & Low & Hi & Hi \\
LIT, PL, HU & Med-Hi & All & Hi & Hi & Hi \\
D(MC) & Med & Med & Hi & Med & Low \\
\hline
\end{tabular}

dummies do not contribute much to the interpretation, but one must bear in mind that they also serve a purpose of capturing convergence.

Moving ahead 3 years, we see a strengthening of the current EMU members core in cluster I. Germany, France, Netherlands and Austria become increasingly similar with coefficients above 0.65 . They are joined by Ireland (47 per cent), which scores also average on all the variables, except for public debt, which although reduced from the previous period, still remains high. Spain and Portugal shift away, towards cluster II and VI, because of high inflation, interest rate and budget deficit. The Czech Republic, Poland and Finland join the Dummy(MC) mainly due to close to 3 per cent deficits, high exchange rate volatility. The Czech Republic shows also close resemblance ( 24 per cent) to cluster II, that is Estonia, Latvia and Lithuania, which achieved significant nominal stabilization, reducing inflation to low, maintaining very low government debt but also relatively high deficit. Belgium and Italy in cluster II still exhibit very high public debt and deficit, again with some (21 per cent) resemblance of the latter to Greece, also with a very high debt and deficit, but clustered separately due to very high inflation and interest rates. Cluster VI contains countries with still persisting high inflation and interest

Table 8. MC 8 years before EMU - cluster characteristics

\begin{tabular}{lccccc}
\hline \multirow{1}{*}{ Hard Clusters } & Budget & Public & Nominal & Interest & \multirow{2}{*}{ Inflation } \\
& Deficit & Debt & Ex. Vol. & Rate & \\
\hline AUS, GER, NL, FR, SLN, SP & Med & Med-Hi & Low-Med & Med-Low & Med-Low \\
IT, BEL & Hi & Hi & Low & Med & Med-Hi \\
LIT, LAT, EST & Hi-Med & Low & Med-Hi & Med-Low & Low-Med \\
D(MC), PL, CZ, FIN & Med & Low-Med & Hi & All & All \\
HU, SLK, PT & Med-Hi & Med-Hi & Med-Hi & Hi & Hi \\
D(0) & Low & Low & Low & Low & Low \\
GR & Hi & Hi & Med & Hi & Hi \\
\hline
\end{tabular}


rates, and relatively high values of all other variables - these economies are not converging, at least not as quickly and are still characterized by a significant amount of instability. They include Hungary, Slovakia (which actually diverged, mainly due to a jump in inflation and interest rate), and to a lesser degree Poland ( 23 per cent) and Slovenia(17 per cent). They show some correspondence with the high inflation and interest rate Iberic countries.

Within 5 years of membership, the CEECs managed to achieve further stabilization of the economies. The EU members generally ran high deficits, thus the core is joined by Belgium (though only marginally - 30 per cent) and by Ireland which managed to further reduce its debt burden. Italy, Portugal, Spain and Hungary strengthen their resemblance, thus idea of formation of the southern periphery seems justifiable.

Poland stays close to the Dummy(MC), but fails to converge further. Finland, Czech Republic, Latvia and Lithuania seem to remain among the prime candidates in terms of readiness, and the three CEECs in cluster III show high similarity with cluster II, that is Estonia and Slovakia, mainly due to low public debt and similar interest rates.

Thus, overall applying cluster analysis to Maastricht criteria, yields:

Table 9. MC 5 years before EMU - cluster characteristics.

\begin{tabular}{lccccc}
\hline \multicolumn{1}{c}{ Hard Clusters } & $\begin{array}{c}\text { Budget } \\
\text { Deficit }\end{array}$ & $\begin{array}{c}\text { Public } \\
\text { Debt }\end{array}$ & $\begin{array}{c}\text { Nominal } \\
\text { Ex. Vol. }\end{array}$ & $\begin{array}{c}\text { Interest } \\
\text { Rate }\end{array}$ & \multirow{2}{*}{ Inflation } \\
\hline NL, AUS, FR, GER, BEL, IRL & All & Hi-Med & Low-Med & Low-Med & Low-Med \\
FIN, CZ, LAT, LIT & All & Low & Hi & Low-Med & Low \\
SLK, EST & Low & Low & Med & Low-Med & Hi-Med \\
PT, SP, HU, IT & Hi & Hi-Med & Hi-Med & Hi-Med & Hi \\
SLN & Low & Low & Low & Hi & Hi \\
D(MC), PL & Med & Med & Hi & Hi-Med & Hi-Med \\
D(0) & Low & Low & Low & Low & Low \\
GR & Hi & Hi & Med & Hi & Hi \\
\hline
\end{tabular}

Table 10. MC Analysis - two first PCs

\begin{tabular}{ccc}
\hline MC & \multicolumn{2}{c}{2 first components } \\
\hline & 11 years & 5 years \\
$1^{\text {st }}$ var. explained & 48.57 & 49.53 \\
$2^{\text {nd }}$ var. explained & 34.11 & 22.73 \\
\hline & Bartlett's test p-value \\
\hline $\mathrm{n}=2$ & 0.00 & 0.05 \\
$\mathrm{n}=3$ & 0.08 & 0.08 \\
\hline
\end{tabular}


- the core: Germany, France, Austria and Netherlands, with Ireland within reach but still not coping with the public debt criteria and Belgium generally stable with the non-fiscal criteria, but extremely excessive with debt;

- southern periphery: not entirely homogenous - Portugal, Spain, Italy joined by Hungary with some resemblance to Greece - generally not converging to meet the entry prerequisites. Poland although approaching the Maastricht criteria marginal values is still outside, and in many ways resembles this periphery; - the north/east periphery of leading qualifiers: Finland with the Baltic States together with Czech Republic and Slovakia of which all but the last steadily qualify according to the Maastricht criteria. Slovakia although within reach of meeting the requirements, seems not to follow a steady convergence path, but rather to be fairly unstable;

- Slovenia starting off closer than most CEECs, does not converge;

The PCs analysis results displayed in Table 10(more details in the Appendix) to allow focusing on the first two components, as in both cases they cumulatively explained over 70 per cent of the variance and meeting other previously stated requirements. Bartlett's test suggests 2 dimensions of the data at 95 confidence level in both cases.

The rules of construction of the Readiness index are exactly the same as in the case of the OCA Suitability index, thus also the weaknesses are similar. Dummy(0) acts as the reference - identically to Germany in the previous analysis. Additionally, the Dummy(MC) serves as a cut-off value, but rather one way. More

Table 11. MC Readiness Indexes. Index rescaled for equal Dummy(MC) value. (*signals lower than cut-off $\{$ Dummy(MC) $\}$.

\begin{tabular}{cccccc}
\hline & MC 11 & MC 5 & & MC 11 & MC 5 \\
\hline Austria & $1.48^{*}$ & $1.92^{*}$ & Czech Rep. & $1.88^{*}$ & $1.50^{*}$ \\
Belgium & 2.40 & 2.42 & Estonia & 2.76 & $0.95^{*}$ \\
Finland & $1.27^{*}$ & $2.06^{*}$ & Hungary & 4.32 & 2.70 \\
France & $1.14^{*}$ & $1.68^{*}$ & Latvia & 3.36 & $1.78^{*}$ \\
Germany & $1.12^{*}$ & $1.78^{*}$ & Lithuania & 3.98 & $1.06^{*}$ \\
Greece & 4.11 & 4.05 & Poland & 3.64 & 2.48 \\
Ireland & $1.66^{*}$ & $1.68^{*}$ & Slovakia & $1.65^{*}$ & $1.39^{*}$ \\
Italy & 3.06 & 3.38 & Slovenia & 2.56 & 2.46 \\
Netherlands & $1.81^{*}$ & $1.93^{*}$ & Dummy(0) & $0.00^{*}$ & $0.00^{*}$ \\
Portugal & 2.51 & 2.86 & Dummy(MC) & 2.21 & 2.21 \\
Spain & $1.96^{*}$ & $2.49^{*}$ & & & \\
\hline
\end{tabular}


precisely, due to the fact of reducing the dimensions to 1 , we can only be certain that a value of the index above the one of Dummy(MC) means not complying with the criteria. In the opposite case, when the value is smaller, this does not necessarily mean meeting the requirements, solely that a country is close to fulfilling them - usually the closer, the smaller the index, but it need not be so in every case. Moreover, the MC 5 years index is rescaled, for the Dummy(MC) values to be equal - in order to facilitate comparison.

Comparing the indexes over the 6 years yields the following:

- diverging- Austria, Finland, France and Germany generally qualifying and Italy, Portugal and Spain not qualifying.

- converging- all CEECs with the exception of Slovenia, of which only Hungary and Poland do not qualify.

- stable- of which Ireland and Netherlands close to fulfillment, Slovenia, Belgium and Greece not fulfilling.

Significant stabilization of the CEECs, resulted in substantial convergence towards fulfilling the requirements. Within 5 years before the EMU accession most of these countries seem well capable of meeting the entry conditions, the leader being Estonia. Generally the Baltic States, Czech Republic and less stably Slovakia persist in nominal convergence and seem to should have less trouble to qualify then most EU members did. As for the others, the main obstacles remaining budget deficits and marginally high public debt levels in Poland and Hungary, as well as high inflation in Slovenia. Overall, however, the CEECs do not seem to perform worse than any of the southern EU states. This, suggests that all should be capable of qualifying, though for the three laggers it may require a large effort - whether it will be fiscal contraction or inflation battling. The fact that as far as 5 years before entry, the CEECs seem more ready, may also be a sort of signalling. Being relatively young, developing economies they are generally regarded as less credible and stable. In light of the two facts:

1. the still uncertain result of the ongoing debate whether the enlargement countries should be allowed to enter the EMU as quick as possible and whether it is optimal from the current members point of view,

2. assuming significant gains from adopting the common currency for the CEECs, and the will to materialize them as fast as possible, the transition economies may be more determined to show(signal) that they are in fact ready for the Eurozone. 
Figure 5. Mapping of MC index for CEEC accession countries and EMU members 11 years before membership. Lower number (lighter color) indicates 'better' in terms of MC Criteria. Black - not classified. \{Own calculations $\}$

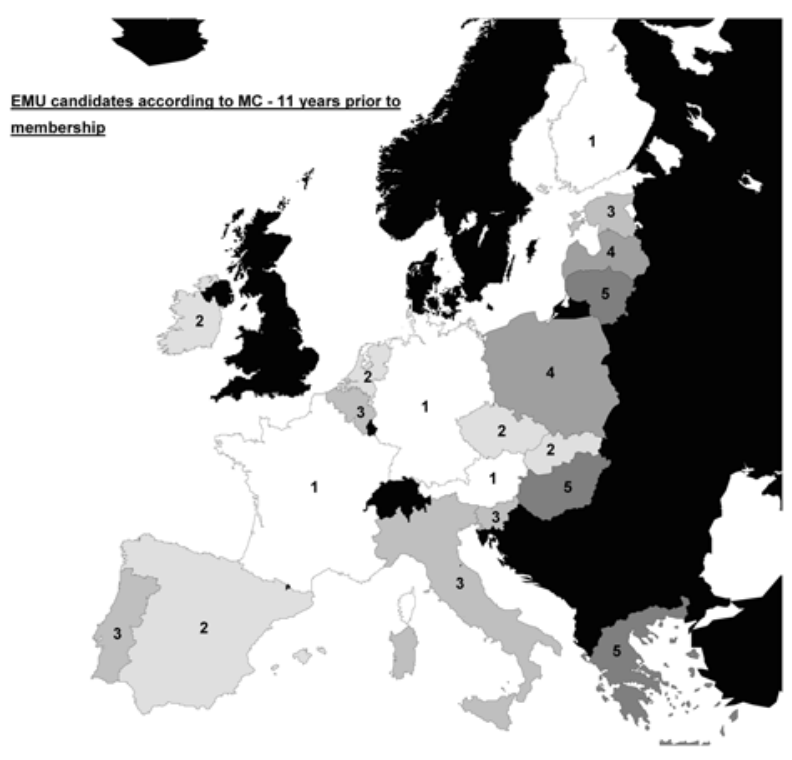

As can be seen in Figures 5 and 7, there are clear differences, between the convergence of countries according to Readiness and Suitability indexes. The 'nominal' structure is not concentric, though does exhibit a strengthening southern periphery. The northern countries, found peripheral in terms of OCA criteria, look most ready in terms of Maastricht requirements. To put it briefly, perhaps not part of the Optimum Currency Area, as defined by theory, nevertheless they need the least effort to fulfill the criteria and qualify. As for the 'core' countries, most are within reach of qualifying, though despite managing to reduce government debt, many remain in excess of the Maastricht requirement.

The Baltic States converge to the northern periphery, eventually outperforming it in terms of Maastricht criteria. Czech Republic and Slovakia, are, in terms of our index, ready 11 years before accession, and confirm this performance 5 years before. Over the 6 years Poland and Slovenia, but especially Hungary join the southern periphery in terms of the used variables. However, starting from a more unsuitable position Hungary and Poland steadily converge towards fulfilling the criteria, whereas the southern EU members show no such sign within 5 years of EMU membership.

The plot according to the two first principal components, 5 years prior to 
Figure 6. Comparison of clustering and principal components results. Maastricht criteria, CEEC accession countries and EMU members, 11 years before membership. First two components explain 83 per cent of variance. Different symbols indicate separate hard clusters. \{Own calculations\}

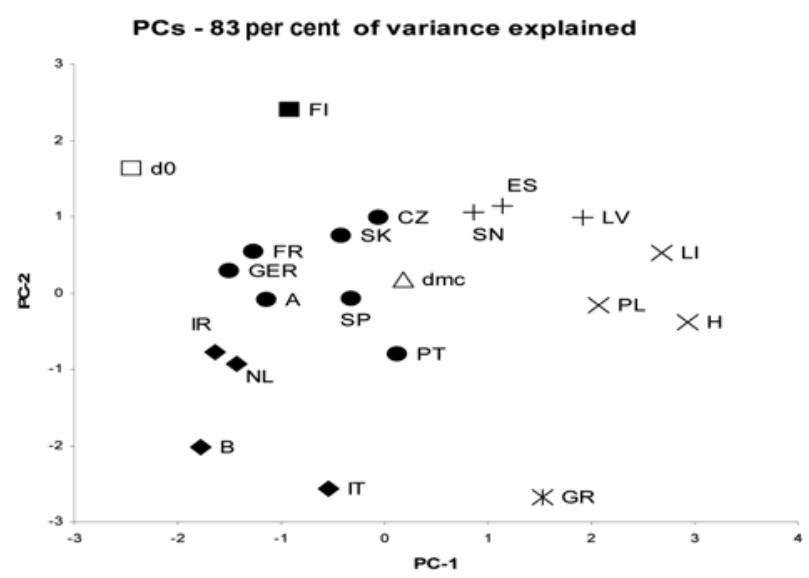

Figure 7. Mapping of MC index for CEEC accession countries and EMU members 5 years before membership. Lower number (lighter color) indicates 'better' in terms of MC Criteria. Black - not classified. \{Own calculations\}

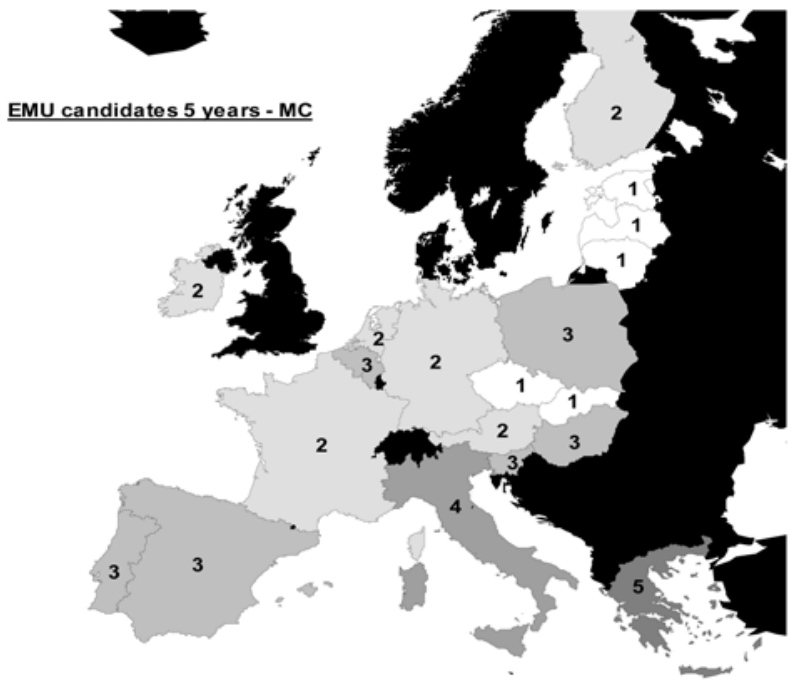

accession is presented in Figure 8, and should be confronted with Figure 6. Confirming the previous findings, even the core EU countries perform somewhat poorer in terms of nominal criteria than some of the CEECs. Spain, Hungary and Portugal show high similarity, and together with Italy and to a lesser extent Greece, seem to constitute the 'nominal' southern periphery - very similar to the 'real' one. 
Figure 8. Comparison of clustering and pricipal components results. Maastricht criteria, CEEC accession countries and EMU members, 5 years before membership. First two components explain 72 per cent of variance. Different symbols indicate separate hard clusters. \{Own calculations\}

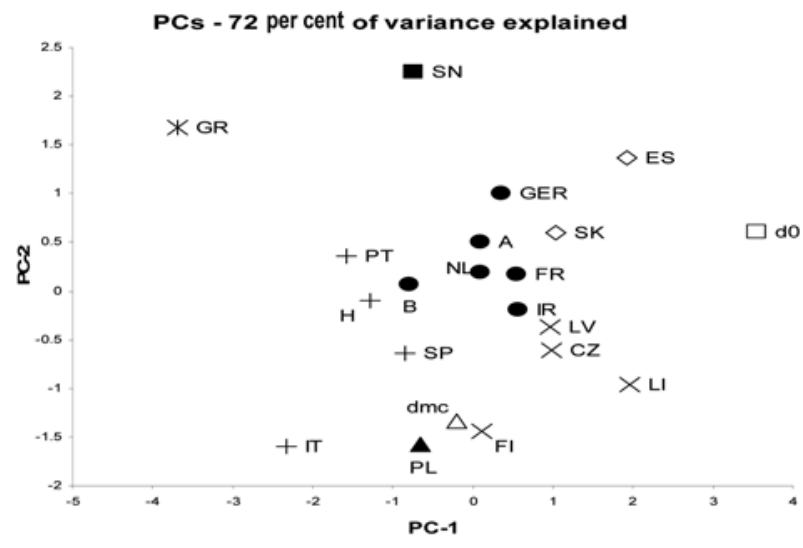

Slovenia is also fairly peripheral nominally, but shows less resemblance to the others. The previously found 'real' core and northern periphery countries seem well capable of fulfilling the criteria, especially if we consider that de facto the debt criteria was treated lightly. Poland is not qualifying, but showing significant convergence, and sharing some of the features of the southern periphery. Summing up, in nominal convergence analysis we find:

- the core: consisting of Germany, France, Austria, Belgium and Netherlands, joined by Czech Republic and Slovakia, together with the northern periphery: Ireland, Baltic States and Finland which actually seem to have less problem to meet the MC;

- the southern periphery: consisting of Italy, Spain, Portugal, Hungary to a lesser extent Greece and Slovenia, but also to some extent Poland which is close to MC cut-off values;

It is also worth noting that the findings confirm both nominal and real similarities between Czech Republic and Slovakia, and also between the Baltic States - which should not be surprising, as these economies not only show resemblance in many fields, but also, not so long ago formed parts of other countries and currency unions. 


\section{Results Compared}

The comparison with previous work is not straight forward - there have not been noticeable attempts to judge suitability and readiness of CEECs for the EMU relative to current members. Nevertheless, the results of this seem fairly in line with previous attempts of operationalizing nominal and real convergence for these groups of countries separately. Artis and Zhang(1998b) find a similar pattern throughout the current EMU members, and the core-periphery terminology within the EMU candidates has been actually adopted from this paper. In terms of OCA criteria, applied within a shorter period before the EMU, they discover a similar pattern of a core composed of Germany (by default), France, Netherlands, Belgium and Austria, and a southern periphery - Portugal, Spain, Italy and also Greece. The northern periphery found is Finland and Ireland together with Denmark, Sweden and the U.K. which are not part of interest in this paper. Including solely EU countries allows for the use of better data, especially business cycles correlation and labor market flexibility measures, but the similarity of their results yield support to the above findings. In terms of the Maastricht criteria, their result is slightly different. Overall, however, the most appropriate period to relate to our results is the analysis conducted by Artis and Zhang(1998b) for 1990-97, as the others (1995-97 and 1997) do not even overlap our sample years. This over-time average analysis is a slightly different approach, but generally they find Germany, France, Austria, Belgium, the Netherlands and Ireland in the core, Spain Portugal and Italy together with Finland in the periphery and Greece as an outlier. The fact that above results are similar but stronger then the ones in our paper can be attributed to the fact that our dataset is bigger, much more variant and diverse, and in fact of poorer quality.

A cluster analysis of CEECs in search for nominal and real convergence is conducted by Boreiko(2003). Though, an over time average, the results for periods 1998-2001 and 2001 can be compared to the above analysis. Firstly, in terms of real convergence the author finds Czech Republic, Estonia, Hungary and Slovenia as the best performers, sometimes joined by Slovakia. The analysis above confirms the Czech Republic and Slovakia as most suitable according to the OCA, followed by Estonia and Hungary, but fails to find Slovenia in the optimal group, as it exhibits excessive inflation and low labor market flexibility (a variable not used by Boreiko). As for the Maastricht criteria, Boreiko (2003) finds the Baltic States and Slovenia as the best performing. Our analysis confirms the Baltic States as 
undoubted leaders, though are joined by Czech Republic and Slovakia. It must be noted that we base upon more recent data, which recognizes its closeness, but fails to find Slovenia a leader, mainly due to persistent high inflation and interest rate. Despite finding Slovakia a good performer in the last period (2002) we do realize its unstable path towards the nominal criteria, therefore do not claim its readiness strongly. As for the Czech Republic, it shows persistent convergence, however still maintains an excessive budget deficit. As scoring high on the other criteria, this single violation, seems to matter less in our PC analysis, though consistently with Boreiko(2003) it is ranked lower then the Baltic States. Overall, the results are fairly similar, but it noted that the differences in exact results may arise to different methodology, time horizon and dataset.

Bayoumi and Eichengreen(1996a) use exchange rate deviation predictions based upon the estimated historical relation between this variable and standard deviation in real output difference, sum of the absolute differences in the shares of agricultural, mineral, and manufacturing trade in total merchandise trade, the mean of the ratio of bilateral exports to domestic GDP and the mean of the of the GDPs, all relative to Germany, in order to develop an OCA index and rank countries. Therefore, using the following bilateral nominal exchange rate equation:

$$
S D\left(e_{i j}\right)=\alpha+\beta_{1} S D\left(y_{i}-y_{i}\right)+\beta_{2} D I S S I M_{i j}+\beta_{3} T R A D E_{i j}+\beta_{4} S I Z E_{i j}
$$

on extrapolated independent variables, the authors associate low need for exchange rate deviations with high suitability in terms of OCA criteria. Table 12 displays the comparison between our OCA suitability index and an OCA index from Bayoumi and Eichengreen (1996b). Although the correlation coefficients do not seem outstandingly high, they can be seen as supportive: firstly the groups of countries found most and least suitable are very similar, and secondly the fact of the actual values correlated with a coefficient above 0.40 , despite a use of a very different approach, and not even exactly the same years, is in fact encouraging.

Overall, the results are consistent with previous findings, but contribute towards

Table 12. OCA Index comparison with Bayoumi and Eichengreen (1996)

\begin{tabular}{lcccc}
\hline & OCA index (1988) & $\begin{array}{c}\text { B\&E OCA } \\
\text { index(1987) }\end{array}$ & OCA index (1994) & $\begin{array}{c}\text { B\&E OCA } \\
\text { index(1995) }\end{array}$ \\
\hline $\begin{array}{l}\text { Correlation } \\
\text { (only EMU) }\end{array}$ & 0.48 & & 0.42 & \\
Most suitable & $\begin{array}{c}\text { Netherlands Austria } \\
\text { France Belgium }\end{array}$ & $\begin{array}{c}\text { Netherlands } \\
\text { Belgium Austria }\end{array}$ & $\begin{array}{c}\text { France Belgium } \\
\text { Letherlands Austria }\end{array}$ & $\begin{array}{c}\text { Netherlands } \\
\text { Belgium Austria }\end{array}$ \\
Least Suitable & Finland Greece & Finland Spain & Finland Greece & Finland Spain \\
\hline
\end{tabular}


a more rigorous and informative assessment of both real and nominal performance of CEECs when approaching EMU membership.

\section{Conclusions}

The comparative statics exercise performed above was intended to find how Central European EU candidate countries fit in the partition believed to exist among EMU members It aimed to explain the convergence paths towards Eurozone accession and assess the relative suitability and readiness of these states for adopting the Euro. This would yield insight on possible future inhomogeneities and policy pressures in the future union, potential gains and losses from joining and problems associated with fulfilling the entrance criteria as well as complying with the SGP or any other stability agreement that may replace it.

Certainly, limitations to the interpretation of the results exist. Among them, the sheer fact that countries not seeming suitable for a common currency, may actually profit most from joining it. Secondly, the data period available for analysis is short, especially for measuring business cycle correlation - but not much can be done about this. Thirdly, if we believe the story of the endogeneity of OCA theory, than despite that the methodology used seems to reduce this problem significantly, we may be more reserved to trust the variables used. Nevertheless, the exercise seems interesting and worth the trade-off.

Summarizing: in this paper we find that the CEECs exhibit quite strong convergence towards both fulfilling the nominal requirements as well as to being suitable for the European currency area. The transition economies blend in well in core-periphery partition of the EMU members. When assessing suitability according to OCA criteria the Central European states fit nicely in the concentric, geographical pattern that can be observed within 5 years before entry. The leaders in real convergence are the Czech Republic, Slovakia and Estonia, which become increasingly alike the core. In nominal convergence, the Baltic States converge rapidly, to eventually outperform most EU members, similarly to Czech Republic, which starts of from a more stable economy and Slovakia. However in case of the latter, the convergence is unstable during the period. Hungary is found strongly present in the southern periphery in both real and nominal terms, though its convergence path suggests it may move towards the core, at least in terms of MC readiness. Slovenia starts off close in terms of both criteria, from a relatively privileged state of economy, but shows little convergence. Poland is converging in 
terms of OCA criteria, but less in Maastricht criteria and shows some similarity with the southern periphery, especially concerning the fiscal policy stance. Latvia and Lithuania, leading in nominal convergence, in terms of real variables drift strongly towards neighboring Finland and the northern periphery in general.

It must be emphasized that, though at the start of analysis most CEECs are certainly less prepared and suitable than current EMU members were. However, within the 6 years examined, they become more suitable and ready then southern European countries where upon 5 years before Eurozone entry. In some cases, especially nominal criteria, they manage to outperform current members. Thus, according to the analysis conducted above, the prime candidates suitable for the EMU, that should not have problems being ready to satisfy the Maastricht requirements can be expected to be Estonia and Czech Republic, and less confidently Slovakia. These states converge towards the strict core. Hungary, Slovenia and Poland will require more effort in order to comply with entry conditions, but if successful, the first two, Slovenia especially, should be joining the southern periphery, while Poland should form part of the core.

The remaining Baltic States - Lithuania and Latvia join Finland and Ireland in the northern periphery but should not have problems in qualifying for the EMU.

\section{Acknowledgments}

The author would like to express his gratitude to Prof. Michael J. Artis (IUE), for his advice and guidance, contributing to this paper.

Received 29 January 2004, Accepted 29 March 2004

\section{References}

Artis M.J., Zhang, W. (1998a), Core and Periphery in EMU: A Cluster Analysis, EUI Working Paper RSC No. 98/37

Artis M.J., Zhang W. (1998b), Membership of EMU: A Fuzzy Clustering Analysis of

Alternative Criteria, Journal of Economic Integration, 17, 1, March 2002, 54-79

Boreiko D. (2003), EMU and Accession Countries: Fuzzy Cluster Analysis of Membership, International Journal of Finance and Economics, 4/2003, Vol. 8, p. 309-325.

Bayoumi T., Eichengreen, B., (1996a), Ever Closer to Heaven? An Optimum-CurrencyArea Index for European Countries, Center for Intenational and Development 
Economics Research, Paper no. C96-078.

Bayoumi T., Eichengreen B. (1996b), Operationalizing the Theory of Optimum Currency Areas, CEPR Discussion Paper, No. 1484,

Bertola G. (1989), Factor Flexibility, Uncertainity and Exchange Rate Regimes, in A European Central Bank? Perspectives on Monetary Unification after ten years of the EMS, De Cecco, M. and Gioviannini, A.

Bratkowski A., Rostowski J. (2002), The EU Attitude to Unilateral Euroization.

Misunderstandings, Real Concerns and Sub-optimal admission Criteria, Economics of Transition, Vol. 10 (2), p. 445-468,

Buiter W.G., Corsetti G., Roubini N., (1992), 'Excessive Deficits': Sense and Nonsense in the Treaty of Maastricht, CEPR discussion paper, 750,

Coricelli, F. (2002), Exchange Rate Policy During Transition to the European Monetary Union: The Option of Euroization, Economics of Transition, Vol. 10(2), p. 405-417

De Grauwe, P., Lavrac, V., (1999), Inclusion of Central European Countries in the European Monetary Union, 1999 Kluwer Academic Publishers.

Frankel, J., Rose, A. (1997), Is EMU More Justifiable Ex Post than Ex Ante?, European Economic Review 41, p. 753-760

Frankel, J., Rose A. (1998), The Endogeneity of the Optimum Currency Area Criteria,

The Economic Journal, 108, p.1009-1025

Höppner, F., Klawonn, F., Kruse R., Runkler T. (1999) Fuzzy Cluster Analysis

Kauffman, L., Rousseeuw P.J.(1990), Finding Groups in Data - An Introduction to Cluster Analysis, Wiley Series in Probability and Mathematical Statistics 1990.

Krugman, P., Venables A.J. (1993), Integration, Specialization, and the Adjustment, European Economic Review, Vol. 40, nos. 3-5 (April 1996): 959-967,

McKinnon, R. (1963), Optimum Currency Areas, American Economic Review, vol. 53, p. 717-724

Mundell, R. (1961), A Theory of Optimum Currency Areas, American Economic Review, vol. 51, p.509-517

Nicoletti, G., Scarpetta, S., Boylaud, O., (2000) Summary Indicators of Product Market Regulation with an Extension to Employment Protection Legislation, OECD Economics Department Working Papers no. 226.

Nuti, D.M. (2002), Costs and Benefits of Unilateral Euroization in Central Eastern Europe, Economics of Transition, Vol. 10(2), p.419-444

Tavlas, G. (1993), The 'New' Theory of Optimum Currency Areas, The World Economy, 16 , p.663-685 


\section{APPENDIX A: Data sources and description}

Nominal Convergence - MC: 1. Budget deficit as per cent of GDP (Annual) EMU-10 (ex. Greece) 1990-1994 -

IFS (IMF), - 1988-1990 EIU Country Reports - Greece 1990-1996 - Economist Intelligence Unit Country Reports

- CEECs 1996-2002 - DB Research

2. Government Debt as per cent of GDP (Annual) - EMU-10 (ex. Greece) 19881994 - IFS (IMF) - Greece 1990-1996

- Economist Intelligence Unit Country Reports - CEECs 1996-2002 - DB Research

3. Nominal Exchange Rate Volatility a. against ECU till 1999, against Euro 1999-2002 b. monthly data:

- all figures from IFS c. 2 year moving intervals, ending on the year reported d. $\ln (\mathrm{NER}$ ) $-\ln (\mathrm{NERt}-1) \mathrm{e}$.

$\operatorname{STDDEV}() *$.

4. Interest Rate (Annual) a. end of year market lending rate - EMU-10 (ex. Austria), CEEC (ex. 2002) -

WDI (WB) - Austria, CEEC(2002) - National Statistics Offices

5. Inflation - CPI annual per cent change, IFS

Dummy(0) - all variables set equal to 0. Dummy(MC) - all variables set to marginally fulfilling Maastricht

Treaty Criteria requirements, i.e.: Fiscal Deficit $=-3$ per cent of GDP, etc.

Real Convergence - OCA: 1. Business Cycles Correlation Industry Production Index, Monthly - DataStream

a. 8 years, pair wise against Germany: - EMU-10 1986-1994 - Greece 19881996 - CEECs 1994-2002 b. rebased at

initial year $=100 \mathrm{c}$. smoothed using HP filter lambda $=14400 \mathrm{~d}$. correlation reported e. TIME INVARIANT

2. Real Exchange Rate Volatility a. against Germany b. ER = NER(local/ DM)*PPI(local)/PPI(GER) c. sources: - PPI - EMU-11 - IFS, CEECs - DataStream - Nominal Exchange Rate - IFS d. 2year moving intervals, ending on the year reported. e. $\ln ($ ERt)- $\ln ($ ERt-1) f. STDDEV(.)*100

3. Labor Market Flexibility a. figures -WB Doing Business 2004 Report b. TIME INVARIANT c. aggregated index: - duration and no. of procedures required to setup business - cost and minimum capital required to setup business (per cent GDP) - quintile ranking 1-5 (1-most flexible) d. data for Estonia missing - proxied 
by average Lithuania \& Latvia

4. Trade Integration with EMU a. (Import from EMU cif + Export to EMU fob)/ (Import total cif + Export total cif) b. World Trade Analyzer - figures for 2002 not available previous year used.

5. Inflation - see nominal convergence.

\section{APPENDIX B: PC results}

Table 13. Principal components analysis - results

\begin{tabular}{|c|c|c|c|c|c|c|c|c|c|c|c|c|c|c|}
\hline Nominal Cons & vergence - & Maast & richt 1 & Treaty & Criter & ria & & Nom & ninal $C$ & Conver & $\begin{array}{l}\text { gence } \\
\text { Crite }\end{array}$ & $\begin{array}{l}\text { - Maa } \\
\text { eria }\end{array}$ & astricht ' & Treaty \\
\hline $\begin{array}{r}\text { Evaluation } 11 \text { yea } \\
\text { Principal Co }\end{array}$ & $\begin{array}{l}\text { rs prior to } \\
\text { omponents }\end{array}$ & $\begin{array}{l}\text { EMU } \\
\text { Analy }\end{array}$ & $\begin{array}{l}\text { accessi } \\
\text { sis }\end{array}$ & on date & & $\begin{array}{r}\text { Rel } \\
\text { weig } \\
v a\end{array}$ & $\begin{array}{l}\text { lative } \\
\text { shts of } \\
\text { ars. }\end{array}$ & & & & & & $\begin{array}{r}\text { Rela } \\
\text { weights }\end{array}$ & $\begin{array}{l}\text { ative } \\
\text { of vars. }\end{array}$ \\
\hline Variable & 1st $2 \mathrm{n}$ & Id 31 & d 4 & th 5 & \begin{tabular}{l|l} 
th & $1 \mathrm{st}$ \\
\end{tabular} & st PC & 2nd PC & $1 \mathrm{st}$ & 2nd & 3rd & 4th & 5 th & 1 st PC & 2nd PC \\
\hline$\overline{\text { Deficit }}$ & $-0.12-0$. & 130. & 510. & 590. & & 0.06 & 0.06 & 0.48 & -0.47 & -0.17 & -0.53 & -0.48 & 0.24 & \begin{tabular}{|l|}
0.24 \\
\end{tabular} \\
\hline Debt & $0.70-0$ & 680. & $15-0$ & .150. & & 0.38 & 0.34 & 0.35 & -0.16 & -0.74 & 0.25 & 0.49 & 0.17 & 0.08 \\
\hline Nominal EX & $-0.20-0$. & $42-0$. & 790. & 190. & & 0.11 & 0.20 & 0.35 & -0.57 & 0.58 & 0.39 & 0.26 & 0.18 & 0.29 \\
\hline Interest Rate & $-0.66-0.5$ & 510. & $31-0$ & $.47-0$ & 03 & 0.36 & 0.25 & 0.72 & 0.65 & 0.16 & 0.13 & -0.12 & 0.37 & 0.33 \\
\hline Inflation & $0.16 \quad 0.2$ & $29-0$. & $03-0$ & .610. & & 0.09 & 0.14 & 0.08 & 0.11 & 0.22 & -0.70 & 0.67 & 0.04 & 0.06 \\
\hline$\%$ Var. Expl. by PC & $48.6 \quad 34$ & 9. & 945. & 042. & & & & 49.5 & 22.7 & 16.3 & 7.46 & 3.97 & & \\
\hline Cummulative & $48.6 \quad 82$ & 92 & $\begin{array}{ll}6 & 9\end{array}$ & $7.6 \quad 10$ & & & & 49.5 & 72.3 & 88.6 & 96.0 & 100 & & \\
\hline$\overline{\text { Dim. (Barlett) }}$ & $\mathrm{n}=1 \quad \mathrm{n}=$ & $\mathrm{n}=$ & $=3 \quad n$ & & & & & $\mathrm{n}=1$ & $\mathrm{n}=2$ & $n=3$ & $\mathrm{n}=4$ & & & \\
\hline Chi-squ. & 55.938 & 9. & $85 \quad 2$. & & & & & 35.5 & 16.7 & 9.85 & 1.95 & & & \\
\hline p-val. & $0.00 \quad 0.0$ & 000. & $08 \quad 0$. & & & & & 0.00 & 0.05 & 0.08 & 0.38 & & & \\
\hline Real Convergence - & Optimum & Curr & ency $\mathbf{A}$ & rea $\mathrm{Cri}$ & iteria & & & Real C & Conver & rgence & $\begin{array}{l}\text { - Opt } \\
\text { Crite }\end{array}$ & $\begin{array}{l}\text { timum } \\
\text { eria }\end{array}$ & Curr & y Area \\
\hline $\begin{array}{l}\text { Evaluation } 11 \text { years } \\
\text { Principal Componen }\end{array}$ & $\begin{array}{l}\text { prior to EN } \\
\text { its Analysis }\end{array}$ & MU ac & cession & date* & & & $\begin{array}{l}\text { elative } \\
\text { ights of } \\
\text { vars. }\end{array}$ & & & & & & $\begin{array}{r}\text { Rela } \\
\text { weights }\end{array}$ & $\begin{array}{l}\text { ative } \\
\text { of vars. }\end{array}$ \\
\hline Variable & $1 \mathrm{st}$ & 2nd & $3 r d$ & 4 th & 5 th & $\mid \begin{array}{l}1 \mathrm{st} \\
\mathrm{PC}\end{array}$ & 2nd PC & 1st & 2nd & $3 \mathrm{rd}$ & 4 th & 5 th & 1st PC & 2nd PC \\
\hline Business Cyc. & -0.26 & 0.56 & -0.32 & -0.52 & 0.49 & \begin{tabular}{|c|c|}
9 & 0.1 \\
6
\end{tabular} & 0.28 & -0.12 & 0.34 & -0.55 & -0.58 & -0.49 & 0.07 & 0.18 \\
\hline Real EX & -0.10 & 0.29 & 0.68 & 0.42 & 0.51 & $1 \quad \begin{array}{c}0.0 \\
6\end{array}$ & 0.14 & -0.81 & 0.37 & 0.13 & -0.10 & 0.42 & 0.47 & 0.19 \\
\hline Labor Mkt. & 0.93 & 0.35 & 0.05 & -0.11 & 0.01 & $1 \begin{array}{c}0.5 \\
7\end{array}$ & 0.17 & 0.32 & 0.82 & 0.41 & 0.17 & -0.17 & 0.18 & 0.43 \\
\hline Trade Int. & -0.15 & 0.13 & 0.63 & -0.60 & -0.45 & $\begin{array}{cc}5 & 0.0 \\
9\end{array}$ & 0.06 & 0.47 & 0.17 & -0.23 & -0.40 & 0.73 & 0.27 & 0.09 \\
\hline Inflation & -0.19 & 0.68 & -0.18 & 0.42 & -0.54 & $4 \mid \begin{array}{c}0.1 \\
2\end{array}$ & 0.34 & -0.02 & 0.23 & -0.68 & 0.68 & 0.12 & 0.01 & 0.12 \\
\hline \% Var. Expl. by PC & 43.46 & 27.6 & 19.2 & 6.47 & 3.36 & & & 49.7 & 24.8 & 15.8 & 5.86 & 3.75 & & \\
\hline Cumulative & 43.46 & 71.0 & 90.2 & 96.6 & 100 & & & 49.7 & 74.6 & 90.4 & 96.3 & 100 & & \\
\hline$\overline{\text { Dim. (Barlett) }}$ & $\mathrm{n}=1$ & $\mathrm{~N}=2$ & $\mathrm{n}=3$ & $\mathrm{n}=4$ & & & & $\mathrm{n}=1$ & $\mathrm{n}=2$ & $\mathrm{n}=3$ & $\mathrm{n}=4$ & & & \\
\hline Chi-squ. & 33.44 & 22.4 & 13.9 & 1.89 & & & & 36.1 & 19.1 & 10.1 & 0.89 & & & \\
\hline p-val. & 0.00 & 0.01 & 0.02 & 0.39 & & & & 0.00 & 0.02 & 0.07 & 0.64 & & & \\
\hline
\end{tabular}

